\title{
Topical non-steroidal anti-inflammatory drugs for analgesia in traumatic corneal abrasions (Review)
}

Wakai A, Lawrenson JG, Lawrenson AL, Wang Y, Brown MD, Quirke M, Ghandour O, McCormick R, Walsh CD, Amayem A, Lang E, Harrison N

Wakai A, Lawrenson JG, Lawrenson AL, Wang Y, Brown MD, Quirke M, Ghandour O, McCormick R, Walsh CD, Amayem A, Lang E, Harrison N.

Topical non-steroidal anti-inflammatory drugs for analgesia in traumatic corneal abrasions.

Cochrane Database of Systematic Reviews 2017, Issue 5. Art. No.: CD009781.

DOI: 10.1002/14651858.CD009781.pub2.

www.cochranelibrary.com 
TABLE OF CONTENTS

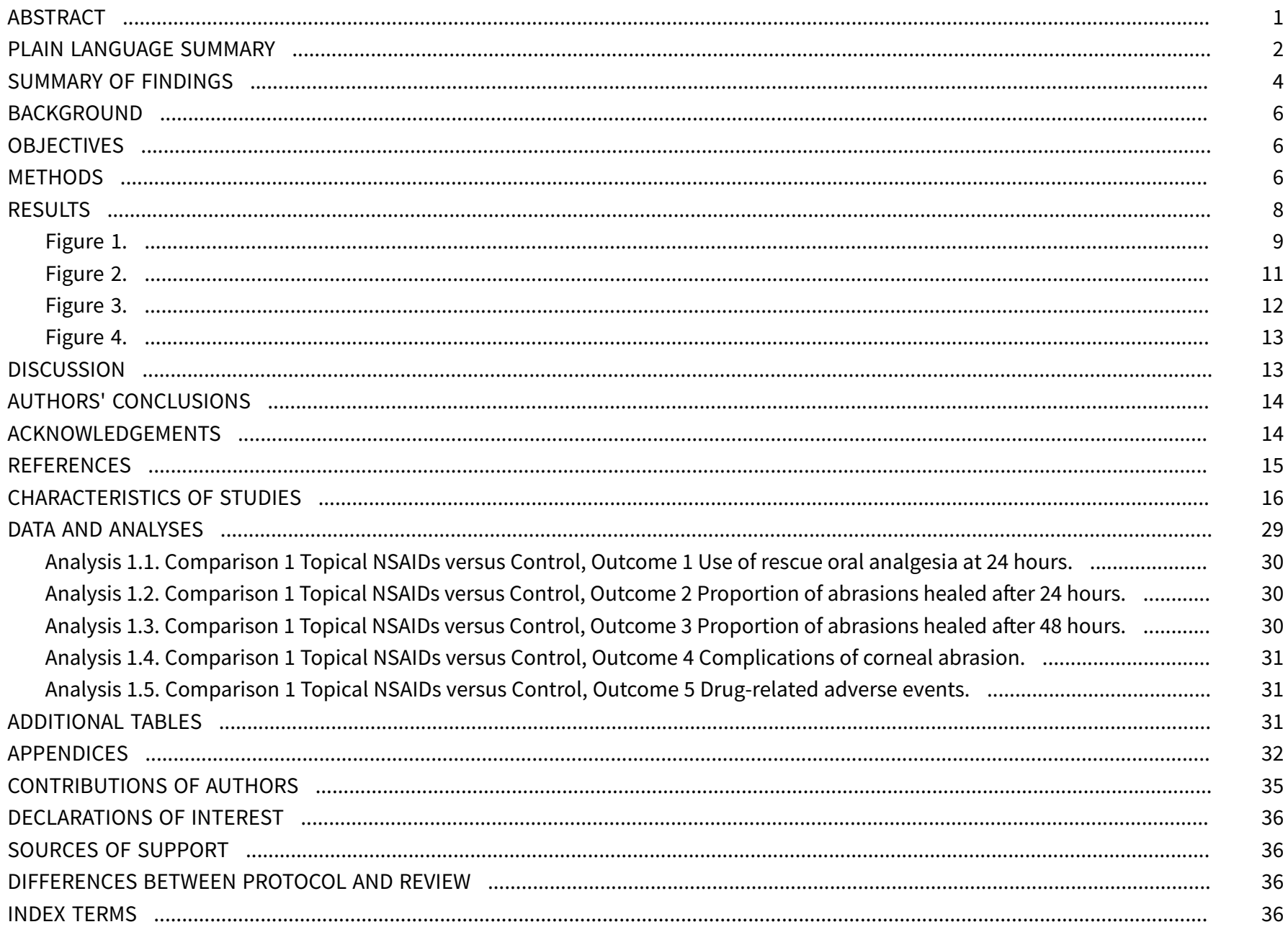


[Intervention Review]

\title{
Topical non-steroidal anti-inflammatory drugs for analgesia in traumatic corneal abrasions
}

\author{
Abel Wakai ${ }^{1}$, John G Lawrenson², Annali L Lawrenson³ ${ }^{3}$ Yongjun Wang ${ }^{4}$, Michael D Brown ${ }^{5}$, Michael Quirke ${ }^{1}$, Omar Ghandour ${ }^{6}$, Ryan \\ McCormick ${ }^{6}$, Cathal D Walsh 7 , Ahmed Amayem ${ }^{8}$, Eddy Lang ${ }^{9}$, Nick Harrison 10 \\ 1Emergency Care Research Unit (ECRU), Division of Population Health Sciences (PHS), Royal College of Surgeons in Ireland (RCSI), Dublin \\ 2, Ireland. ${ }^{2}$ Applied Vision Research Centre, School of Health Sciences, City University of London, London, UK. ${ }^{3}$ Emergency Department, \\ Epsom General Hospital, Surrey, UK. ${ }^{4}$ Schulich School of Medicine \& Dentistry, Western University, London, Canada. ${ }^{5}$ Department of \\ Emergency Medicine, Michigan State University College of Human Medicine, Grand Rapids, MI, USA. ${ }^{6}$ School of Medicine, Royal College \\ of Surgeons in Ireland (RCSI), Dublin 2, Ireland. ${ }^{7}$ Health Research Institute (HRI) and MACSI, Department of Mathematics and Statistics, \\ University of Limerick, Ireland. ${ }^{8}$ Cumming School of Medicine, University of Calgary, Calgary, Canada. ${ }^{9}$ Department of Emergency \\ Medicine, University of Calgary, Calgary, Canada. ${ }^{10}$ Beaumont Health Emergency Medicine Residency, Beaumont Hospital, Royal Oak, \\ Michigan, USA
}

Contact: Abel Wakai, Emergency Care Research Unit (ECRU), Division of Population Health Sciences (PHS), Royal College of Surgeons in Ireland (RCSI), 123 St. Stephen's Green, Dublin 2, Ireland. awakai@rcsi.ie, abelwakai@beaumont.ie.

Editorial group: Cochrane Eyes and Vision Group.

Publication status and date: New, published in Issue 5, 2017.

Citation: Wakai A, Lawrenson JG, Lawrenson AL, Wang Y, Brown MD, Quirke M, Ghandour O, McCormick R, Walsh CD, Amayem A, Lang E, Harrison N. Topical non-steroidal anti-inflammatory drugs for analgesia in traumatic corneal abrasions. Cochrane Database of Systematic Reviews 2017, Issue 5. Art. No.: CD009781. DOI: 10.1002/14651858.CD009781.pub2.

Copyright @ 2017 The Cochrane Collaboration. Published by John Wiley \& Sons, Ltd.

\section{A B S T R A C T}

\section{Background}

Traumatic corneal abrasions are relatively common and there is a lack of consensus about analgesia in their management. It is therefore important to document the clinical efficacy and safety profile of topical ophthalmic non-steroidal anti-inflammatory drugs (NSAIDs) in the management of traumatic corneal abrasions.

\section{Objectives}

To identify and evaluate all randomised controlled trials (RCTs) comparing the use of topical NSAIDs with placebo or any alternative analgesic interventions in adults with traumatic corneal abrasions (including corneal abrasions arising from foreign body removal), to reduce pain, and its effects on healing time.

\section{Search methods}

We searched the Cochrane Central Register of Controlled Trials (CENTRAL) (which contains the Cochrane Eyes and Vision Trials Register) (2017, Issue 2), MEDLINE Ovid (1946 to 30 March 2017), Embase Ovid (1947 to 30 March 2017), LILACS (Latin American and Caribbean Health Sciences Literature Database) (1982 to 30 March 2017), OpenGrey (System for Information on Grey Literature in Europe) (www.opengrey.eu/); searched 30 March 2017, ZETOC (1993 to 30 March 2017), the ISRCTN registry (www.isrctn.com/editAdvancedSearch); searched 30 March 2017, ClinicalTrials.gov (www.clinicaltrials.gov); searched 30 March 2017 and the WHO International Clinical Trials Registry Platform (ICTRP) (www.who.int/ictrp/search/en); searched 30 March 2017. We did not use any date or language restrictions in the electronic searches for trials.We checked the reference lists of identified trials to search for further potentially relevant studies.

\section{Selection criteria}

RCTs comparing topical NSAIDs to placebo or any alternative analgesic interventions in adults with traumatic corneal abrasions. 


\section{Data collection and analysis}

Two review authors independently performed data extraction and assessed risks of bias in the included studies. We rated the certainty of the evidence using GRADE.

\section{Main results}

We included nine studies that met the inclusion criteria, reporting data on 637 participants.The studies took place in the UK, USA, Israel, Italy, France and Portugal. These studies compared five types of topical NSAIDs ( $0.1 \%$ indomethacin, $0.03 \%$ flurbiprofen, $0.5 \%$ ketorolac, $1 \%$ indomethacin, $0.1 \%$ diclofenac) to control (consisting of standard care and in four studies used placebo eye drops). Overall, the studies were at an unclear or high risk of bias (particularly selection and reporting bias). None of the included studies reported the primary outcome measures of this review, namely participant-reported pain intensity reduction of $30 \%$ or more or $50 \%$ or more at 24 hours. Four trials, that included data on 481 participants receiving NSAIDs or control (placebo/standard care), reported on the use of 'rescue' analgesia at 24 hours as a proxy measure of pain control. Topical NSAIDs were associated with a reduction in the need for oral analgesia compared with control (risk ratio (RR) $0.46,95 \%$ confidence interval (Cl) 0.34 to 0.61 ; low-certainty evidence). Approximately 4 out of 10 people in the control group used rescue analgesia at 24 hours. No data were available on the use of analgesia at 48 or 72 hours.

One trial (28 participants) reported on the proportion of abrasions healed after 24 and 48 hours. These outcomes were similar in both arms of the trial. (at 24 hours RR 1.00 (0.81 to 1.23); at 48 hours RR 1.00 (0.88 to 1.14); low-certainty evidence). In the control group nine out of 10 abrasions were healed within 24 hours and all were healed by 48 hours. Complications of corneal abrasions were reported in 6 studies (609 participants) and were infrequently reported (4 complications, 1 in NSAID groups (recurrent corneal erosion) and 3 in control groups ( 2 recurrent corneal erosions and 1 corneal abscess), very low-certainty evidence). Possible drug-related adverse events (AEs) were reported in two trials (163 participants), with the number of adverse events low (4 AEs, 3 in NSAID group, including discomfort/photophobia on instillation, conjunctival hyperaemia and urticaria, and 1 in the control group, corneal abscess) very low-certainty evidence.

\section{Authors' conclusions}

The findings of the included studies do not provide strong evidence to support the use of topical NSAIDs in traumatic corneal abrasions. This is important, since NSAIDs are associated with a higher cost compared to oral analgesics. None of the trials addressed our primary outcome measure of participant-reported pain intensity reduction of $30 \%$ or more or $50 \%$ or more at 24 hours.

\section{PLAIN LANGUAGE SUMMARY}

\section{Topical non-steroidal anti-inflammatory drugs (NSAIDs) for the treatment of pain in traumatic corneal abrasions}

\section{What is the aim of this review?}

The aim of this Cochrane Review was to find out if topical (applied directly to the surface of the eye) non-steroidal anti-inflammatory drugs (NSAIDs) for traumatic corneal abrasions reduce pain. Cochrane researchers collected and analysed all relevant studies to answer this question. We found nine studies.

\section{Key messages}

It is unclear if using topical NSAIDs is helpful in traumatic corneal abrasions. Topical NSAIDs cost more to use than alternative treatments such as oral pain-killing tablets.

\section{What was studied in the review?}

A corneal abrasion is a scratch on the cornea of the eye. The cornea is the clear window that is in front of the iris, which is the coloured part of the eye. The cornea is important both for vision and for protecting the eye. When a corneal abrasion occurs, it causes significant pain and discomfort. A traumatic corneal abrasion is a corneal abrasion caused by an injury, such as the eye being poked or something like dirt or sand being trapped under the eyelid and scratching the cornea.

NSAIDs are one form of pain management for people with corneal abrasions.They may reduce the pain.

\section{What are the main results of the review?}

The Cochrane researchers found nine relevant studies. Three studies each were from the UK and the USA, one from Italy, one from Israel and one from France/Portugal. These studies used five types of topical NSAIDs ( $0.1 \%$ indomethacin, $0.03 \%$ flurbiprofen, $0.5 \%$ ketorolac, $1 \%$ indomethacin, $0.1 \%$ diclofenac). The studies compared the topical NSAIDs with antibiotic eye drops, artificial tears, eye patching and dummy (placebo) eye drops. Three of the studies were funded by the manufacturer while the other six studies did not report their funding source.

The results of the review show that:

- It is unclear if people treated with topical NSAIDs experience a clinically meaningful reduction in pain compared with people being treated with placebo or standard care (antibiotic eye drops, artificial tears, eye patching) but they may use less oral pain killers.

- Where drug-related side effects, and complications of corneal abrasion (e.g. poor healing or infection) were reported (in two trials), the numbers were low. 
How up-to-date is this review?

Cochrane researchers searched for studies that had been published up to March 2017. 


\section{SUMMARY OF FINDINGS}

\section{Summary of findings for the main comparison. Topical NSAIDs compared to control for analgesia in traumatic corneal abrasions}

\section{Topical NSAIDs compared to control for analgesia in traumatic corneal abrasions}

Patient or population: analgesia in traumatic corneal abrasions

Setting: hospital emergency departments

Intervention: topical NSAIDs

Comparison: placebo/standard care

\begin{tabular}{|c|c|c|c|c|c|c|}
\hline \multirow[t]{2}{*}{ Outcomes } & \multicolumn{2}{|c|}{ Anticipated absolute effects ${ }^{\star}(95 \% \mathrm{Cl})$} & \multirow{2}{*}{$\begin{array}{l}\text { Relative effect } \\
(95 \% \mathrm{Cl})\end{array}$} & \multirow{2}{*}{$\begin{array}{l}\text { No of partici- } \\
\text { pants } \\
\text { (studies) }\end{array}$} & \multirow{2}{*}{$\begin{array}{l}\text { Certainty of } \\
\text { the evidence } \\
\text { (GRADE) }\end{array}$} & \multirow[t]{2}{*}{ Comments } \\
\hline & $\begin{array}{l}\text { Risk with } \\
\text { Placebo/usual } \\
\text { care }\end{array}$ & $\begin{array}{l}\text { Risk with Topical } \\
\text { NSAIDs }\end{array}$ & & & & \\
\hline $\begin{array}{l}\text { Participant-reported pain intensity reduc- } \\
\text { tion of } 30 \% / 50 \% \text { or greater at } 24 \text { hours }\end{array}$ & See comment & See comment & $\mathrm{N} / \mathrm{A}$ & $\mathrm{N} / \mathrm{A}$ & $\mathrm{N} / \mathrm{A}$ & $\begin{array}{l}\text { None of the included } \\
\text { studies reported the } \\
\text { primary outcome mea- } \\
\text { sures for this review }\end{array}$ \\
\hline Use of rescue oral analgesia at 24 hours & 400 per 1,000 & $\begin{array}{l}184 \text { per } 1,000 \\
\text { (136 to } 244)\end{array}$ & $\begin{array}{l}\text { RR } 0.46 \\
(0.34 \text { to } 0.61)\end{array}$ & $\begin{array}{l}481 \\
(4 \mathrm{RCTs})\end{array}$ & $\begin{array}{l}\oplus \oplus \ominus \odot \\
\text { LOW1 }\end{array}$ & - \\
\hline $\begin{array}{l}\text { Use of rescue oral analgesia at } 48 / 72 \\
\text { hours }\end{array}$ & See comment & See comment & $\mathrm{N} / \mathrm{A}$ & $\mathrm{N} / \mathrm{A}$ & $\mathrm{N} / \mathrm{A}$ & $\begin{array}{l}\text { None of the included } \\
\text { studies reported res- } \\
\text { cue analgesia at } 48 \\
\text { hours or at } 72 \text { hours as } \\
\text { an outcome measure }\end{array}$ \\
\hline $\begin{array}{l}\text { Proportion of abrasions healed after } 24 \\
\text { hours }\end{array}$ & 900 per 1,000 & $\begin{array}{l}900 \text { per } 1,000 \\
\text { (729 to } 1,000)\end{array}$ & $\begin{array}{l}\text { RR } 1.00 \\
\text { (0.81 to } 1.23)\end{array}$ & $\begin{array}{l}28 \\
(1 \mathrm{RCT})\end{array}$ & $\begin{array}{l}\oplus \oplus \oplus \ominus \\
\text { LOW1 }\end{array}$ & - \\
\hline $\begin{array}{l}\text { Proportion of abrasions healed after } 48 \\
\text { hours }\end{array}$ & 1,000 per 1,000 & $\begin{array}{l}1000 \text { per } 1,000 \\
(880 \text { to } 1,000)\end{array}$ & $\begin{array}{l}\text { RR } 1.00 \\
\text { (0.88 to } 1.14)\end{array}$ & $\begin{array}{l}28 \\
(1 \mathrm{RCT})\end{array}$ & $\begin{array}{l}\oplus \oplus \oplus \ominus \\
\text { LOW1 }\end{array}$ & - \\
\hline Complications of corneal abrasion & 10 per 1,000 & $\begin{array}{l}4 \text { per } 1,000 \\
\text { (1 to } 29)\end{array}$ & $\begin{array}{l}\text { RR } 0.44 \\
\text { (0.07 to } 2.96)\end{array}$ & $\begin{array}{l}609 \\
(6 \mathrm{RCTs})\end{array}$ & $\begin{array}{l}\oplus \ominus \ominus \ominus \\
\text { VERY LOW } 1,2\end{array}$ & - \\
\hline Drug-related adverse events & 10 per 1,000 & $\begin{array}{l}30 \text { per } 1,000 \\
(3 \text { to } 276)\end{array}$ & $\begin{array}{l}\text { RR } 2.95 \\
(0.32 \text { to } 27.60)\end{array}$ & $\begin{array}{l}163 \\
\text { (2 RCTs) }\end{array}$ & $\begin{array}{l}\oplus \ominus \ominus \ominus \\
\text { VERY LOW } 1,2\end{array}$ & - \\
\hline
\end{tabular}


${ }^{*}$ The risk in the intervention group (and its 95\% confidence interval) is based on the assumed risk in the comparison group and the relative effect of the intervention (and its $95 \% \mathrm{Cl})$.

\section{Cl: Confidence interval; RR: Risk ratio}

\section{GRADE Working Group grades of evidence}

High-certainty: We are very confident that the true effect lies close to that of the estimate of the effect

Moderate-certainty: We are moderately confident in the effect estimate: The true effect is likely to be close to the estimate of the effect, but there is a possibility that it is

substantially different

Low-certainty: Our confidence in the effect estimate is limited: The true effect may be substantially different from the estimate of the effect

Very low-certainty: We have very little confidence in the effect estimate: The true effect is likely to be substantially different from the estimate of effect

\section{Downgraded two levels for limitations in study design and implementation}

2Downgraded one level for imprecision (wide confidence intervals that cross the null effect) 


\section{B A C K G R O U N D}

\section{Description of the condition}

A corneal abrasion results from a disruption in the integrity of the corneal epithelium and generally results from physical external forces scraping the corneal surface (Wilson 2004). Traumatic corneal abrasions are very common ophthalmic injuries and represent a significant healthcare burden to general emergency departments (EDs), ophthalmology emergency departments and General Practitioners (Chiapella 1985; Edwards 1987; Fenton 2001; Shields 1991). In one study, ophthalmic emergencies accounted for $6.1 \%$ of all ED attendances at a district general hospital over a 12 -month period; $65 \%$ of these were trauma-related, of which $24 \%$ were corneal abrasions (Edwards 1987). Traumatic corneal abrasions also represent a significant economic burden on society in general. For example, in the USA, corneal abrasions account for approximately $15 \%$ of all work-related eye diseases that cause missed time from work (Harris 2008).

A traumatic corneal abrasion is also associated with significant patient morbidity. Its diagnosis is suggested by a history of recent ocular trauma (usually unilateral) and subsequent acute pain, tearing, photophobia, foreign body sensation, with or without effects on visual acuity (blurred vision). Other symptoms include: pain with extraocular muscle movement, blepharospasm and headache. Deeper scratches can cause corneal scarring that can impair vision to the point where corneal transplantation is needed. Recurrent corneal erosion may follow corneal trauma and can produce disabling ocular symptoms and predispose the cornea to infection (Watson 2013).

\section{Description of the intervention}

Although current treatment recommendations for traumatic corneal abrasions stress the use of topical antibiotics and topical (ophthalmic) or oral analgesics (Wilson 2004), there is no universal consensus regarding corneal abrasion management (Sabri 1998). Routine use of topical anaesthetics is not recommended, due to recognised corneal complications associated with their use (Pharmakakis 2002; Yagci 2011). Most corneal abrasions heal with the use of topical antibiotics (drops or ointment) and analgesics (topical (ophthalmic) or oral). Regarding management of the pain associated with corneal abrasions, topical ophthalmic nonsteroidal anti-inflammatory drugs (NSAIDs) have demonstrable efficacy, particularly where potential opioid-induced sedation is intolerable (Weaver 2003). However, there is also no consensus regarding management of the pain caused by traumatic corneal abrasions. A national survey of $\mathbf{4 7 0}$ members of the Canadian Association of Emergency Physicians revealed wide variation in pain management preferences for traumatic corneal abrasions; these included oral analgesics (82.1\%), cycloplegics (65.1\%) and topical NSAIDs (52.8\%) (Calder 2004).

There have been scattered reports of adverse effects, including corneal melting, associated with topical NSAIDs, particularly after cataract surgery, concurrent use of topical steroids and prolonged administration (Guidera 2001; Lin 2000). A previous systematic review of the use of the topical NSAIDs for corneal abrasions failed to perform a meta-analysis of adverse effects due to insufficient data (Calder 2005)

\section{How the intervention might work}

Topical NSAID use results in a clinically significant decrease in pain (by an average of $1.3 \mathrm{cms}$ on a standard $10-\mathrm{cm}$ pain scale), a decrease in oral analgesic use and a decrease in requirement for narcotic analgesia (Weaver 2003). Topical NSAID use has been shown to be associated with earlier return to work after a traumatic corneal abrasion (Kaiser 1997).

\section{Why it is important to do this review}

The use of topical NSAIDs for the management of pain in traumatic corneal abrasions is a clinically valid topic for a Cochrane Review for many reasons. Firstly, corneal abrasions are relatively common. Secondly, they are associated with significant morbidity, healthcare costs and societal economic burden. Thirdly, there is a lack of consensus regarding analgesia in traumatic corneal abrasions. Fourthly, as the use of topical ophthalmic NSAIDs is very common, it is important to document any incidence of adverse effects when used in the management of traumatic corneal abrasions. Furthermore, a Cochrane Review that is continuously updated as new evidence is published may lead to clinical practice guidelines which may improve the efficiency and quality of patient care (Edwards 1987; Fenton 2001; Thyagarajan 2006). Moreover, the last non-Cochrane systematic review on this topic was published almost twelve years ago (Calder 2005). This Cochrane Review aims to synthesise the current best evidence, which will be continuously updated as relevant new trials are published, regarding the role of topical NSAIDs for analgesia in traumatic corneal abrasions (including corneal abrasions arising from foreign body removal).

\section{OB JECTIVES}

To identify and evaluate all randomised controlled trials (RCTs) comparing the use of topical NSAIDs with placebo or any alternative analgesic interventions in adults with traumatic corneal abrasions (including corneal abrasions arising from foreign body removal) to reduce pain, and its effects on healing time.

\section{METHODS}

\section{Criteria for considering studies for this review}

\section{Types of studies}

We included RCTs in all languages. A RCT was defined as a study in which participants were allocated to treatment groups on the basis of a method to generate a random sequence (for example, using random-number tables).

We did not include studies with cross-over designs because these are not appropriate designs for the clinical condition of interest in this review and for this research question.

\section{Types of participants}

We included adults aged 18 and over with traumatic corneal abrasion(s) (including corneal abrasions arising from foreign body removal).

\section{Types of interventions}

The target intervention was topical NSAIDs (dose as defined by study authors, either overall daily dose or number of drops per day) in adults with traumatic corneal abrasions (including corneal 
abrasions arising from foreign body removal), compared to the following interventions:

1. Administration of cycloplegics (e.g. cyclopentolate drops, homatropine drops).

2. Administration of oral analgesics (e.g. NSAIDs, opioids, paracetamol/acetaminophen).

3. Administration of ocular lubricants (e.g. artificial tears (hydrogels)).

4. Administration of topical antibiotics (e.g. chloramphenicol, fusidic acid, trimethoprim/polymyxin).

5. Eye patching.

\section{Types of outcome measures}

\section{Primary outcomes}

1. Participant-reported pain intensity reduction of $30 \%$ or more at 24 hours (dichotomous data).

2. Participant-reported pain intensity reduction of $50 \%$ or more at 24 hours (dichotomous data).

\section{Secondary outcomes}

1. Use of 'rescue' analgesia (i.e. oral analgesia) at 24 hours, 48 hours and 72 hours.

2. Percentage/proportion healed after 24 and 48 hours (healing should have been ascertained using fluorescein staining or slitlamp examination).

3. Complications of corneal abrasion (e.g. corneal ulceration, corneal infections, recurrent corneal erosion syndrome) as defined by the study authors.

4. Whether the use of concurrent topical antibiotics (drops or ointments) with additional lubricating effects reduced pain.

\section{Adverse effects (severe, minor)}

We looked for the following adverse effects:

1. Drug-related adverse events (e.g. corneal melting, corneal scarring, allergic conjunctivitis or keratitis secondary to ocular medications).

2. Other adverse events as defined by the study authors.

\section{Search methods for identification of studies}

\section{Electronic searches}

The Cochrane Eyes and Vision Information Specialist conducted systematic searches in the following databases for randomised controlled trials and controlled clinical trials. There were no language or publication year restrictions. The date of the search was 30 March 2017

- Cochrane Central Register of Controlled Trials (CENTRAL; 2017 Issue 2) (which contains the Cochrane Eyes and Vision Trials Register) in the Cochrane Library (searched 30 March 2017) (Appendix 1);

- MEDLINE Ovid (1946 to 30 March 2017) (Appendix 2);

- Embase Ovid (1980 to 30 March 2017) (Appendix 3);

- LILACS (Latin American and Caribbean Health Science Information database (1982 to 30 March 2017) (Appendix 4);

- OpenGrey (System for Information on Grey Literature in Europe) (www.opengrey.eu/; searched 30 March 2017) (Appendix 5);
- ZETOC (1993 to 30 March 2017) (Appendix 6);

- ISRCTN registry (www.isrctn.com/editAdvancedSearch; searched 30 March 2017) (Appendix 7);

- US National Institutes of Health Ongoing Trials Register ClinicalTrials.gov (www.clinicaltrials.gov; searched 30 March 2017) (Appendix 8);

- World Health Organization International Clinical Trials Registry Platform (www.who.int/ictrp; searched 30 March 2017) (Appendix 9).

\section{Searching other resources}

We made additional efforts to identify potential RCTs relevant to the topic from the references (and references of references) cited in primary sources. We did not impose any language restriction.

\section{Data collection and analysis}

\section{Selection of studies}

Two review authors (RM and OG) independently assessed the titles and abstracts of studies identified by relevance and design. We obtained full-text versions of the articles if they appeared to meet the inclusion criteria in the initial assessment of studies. A third review author (AW) evaluated any discrepant judgements.

\section{Data extraction and management}

Two review authors (MB and $\mathrm{MQ}$ ) independently extracted data using a standardised data collection form that included information on the name of the first author, year of publication, study design, study population and study setting. In addition to information pertaining to participant characteristics, study inclusion and exclusion criteria, details of the interventions compared and study outcomes, we extracted information on study methodology. This included the method of randomisation, allocation concealment, frequency and handling of withdrawals, and adherence to the intention-to-treat principle. We resolved disagreements through discussion and in consultation with a third review author (AW) as required.

\section{Assessment of risk of bias in included studies}

Two review authors (MB and MQ) independently assessed and rated the methodological quality of each trial using the Cochrane tool for assessing risk of bias as in Chapter 8 of the Cochrane Handbook for Systematic Reviews of Interventions (Higgins 2011). We judged the quality of the studies by evaluating them for the following domains:

1. Random sequence generation.

2. Allocation concealment.

3. Masking of participants and personnel, and outcome assessment.

4. Incomplete outcome data.

5. Selective outcome reporting.

6. Funding source.

7. Other potential sources of bias.

We evaluated each study and assessed it separately for these domains. We judged each explicitly as follows:

- Low risk of bias.

- High risk of bias. 
- Unclear risk (lack of information or uncertainty over the potential for bias).

We entered the data on what was reported to have happened in the study in the 'Risk of bias' table in Review Manager 5 (Review Manager 5 2014). We present summary figures of the 'risk of bias in included studies' in the review. These provides a context for discussing the reliability of the results of this review. We resolved any disagreement by referring to a third review author (AW) to reach a consensus.

\section{Measures of treatment effect}

We calculated summary estimates of treatment effect with $95 \%$ confidence intervals (Cls) for each comparison. Our measure of treatment effect was the risk ratio (RR) for dichotomous outcomes and the mean difference (MD) for continuous outcomes. Currently the review only includes analysis of dichotomous outcomes.

\section{Unit of analysis issues}

The unit of randomisation was the eye of individual trial participants. We did not anticipate that studies would have more than one eye affected in each individual; however, if this occurred we planned to note it in the review. If studies using a paired design were eligible for inclusion (i.e. studies assigning one eye to treatment and the fellow eye to control), we planned to use the generic inverse variance method to combine the results of such studies with those of studies randomising only one eye for each participant.

\section{Dealing with missing data}

No simple solution exists for the problem of missing data. We planned to handle this problem by contacting the investigators, whenever possible, to ensure that no data were missing for their study. We also planned to make explicit the assumptions of whatever method we used to cope with missing data.

\section{Assessment of heterogeneity}

We evaluated clinical heterogeneity (differences between studies in key characteristics of the participants, interventions or outcome measures). In the absence of clinical heterogeneity, we used the ${ }^{2}$ statistic to describe the percentage of total variation across studies that is due to heterogeneity rather than chance (Higgins 2003). An $1^{2}$ greater than $50 \%$ may represent substantial or considerable statistical heterogeneity (Higgins 2011). The importance we placed on the observed value of 12 depended on (i) magnitude and direction of effects, and (ii) strength of evidence for heterogeneity ( $P$ value from the $\mathrm{Chi}^{2}$ test and confidence interval for $\mathrm{I}^{2}$ ).

We also used visual inspection of the graphic representation of studies with their $95 \%$ Cls to assess heterogeneity. We generated tables and graphs using the analysis module included in RevMan (Review Manager 5 2014). We represent pooled risk ratios pictorially as a 'forest plots' to permit visual examination of the degree of heterogeneity between studies.

\section{Assessment of reporting biases}

We assessed reporting bias through careful attention to quality assessment, particularly methodology. We planned to use funnel plot analysis to assess publication bias if there were more than 10 studies included in the meta-analysis. We also planned to use the
Egger test (Egger 1997) to assess funnel plot asymmetry. A thorough search for unpublished studies through grey literature searches and contact with known experts in the field also helped to reduce the risk of publication bias.

\section{Data synthesis}

The results concentrate on the objectives and comparisons specified in the protocol for our review. We pooled data using a random-effects model, because it was likely that the effects of topical NSAIDs may vary between studies. The random-effects model takes into account between-study variability as well as within-study variability. When there were three or fewer trials, we used a fixed-effect model. We performed meta-analyses using RevMan 5 software (Review Manager 5 2014).

\section{Subgroup analysis and investigation of heterogeneity}

We planned to investigate heterogeneity by performing two subgroup analyses based on intuitive reasons. Firstly, we planned to perform subgroup analysis of different types of topical NSAIDs (for example, subgroup analysis of topical diclofenac and topical ketorolac). Secondly, we planned to perform subgroup analysis of traumatic corneal abrasions with different aetiologies, based on whether the abrasions are iatrogenic (arising from foreign body removal) or non-iatrogenic in origin.

\section{Sensitivity analysis}

Finally, we planned to perform sensitivity analyses to test how sensitive the results were to reasonable changes in the assumptions that we made and in the methods for combining the data (Lau 1998). We planned to perform sensitivity analysis for randomised versus quasi-randomised studies and eventually goodquality studies versus poor-quality studies.

\section{Summary of findings}

We used the principles of the GRADE system (Lau 1998) to assess the quality of the body of evidence associated with the primary outcome measure of this review (pain relief), and constructed a 'Summary of findings' (SoF) table using the GRADE software (GRADEpro 2014). The GRADE approach appraises the quality of a body of evidence based on the extent to which one can be confident that an estimate of effect or association reflects the item being assessed. The quality of a body of evidence considers within-study risk of bias (methodological quality), the directness of the evidence, heterogeneity of the data, precision of effect estimates and risk of publication bias.

\section{RESULTS}

\section{Description of studies}

\section{Results of the search}

The electronic searches yielded 465 references (Figure 1). After 134 duplicate were removed the Cochrane Information Specialist (CIS) screened the remaining 331 records and removed 267 references which were not relevant to the scope of the review. We screened the remaining 64 references and obtained the full-text reports of nine references for further assessment. We assessed the nine full-text versions of the abstracts and all met the a priori criteria for inclusion in the final analysis. See Characteristics of included studies for details. We did not identify any ongoing studies from our searches of the clinical trials registries. 
Figure 1. Study flow diagram.

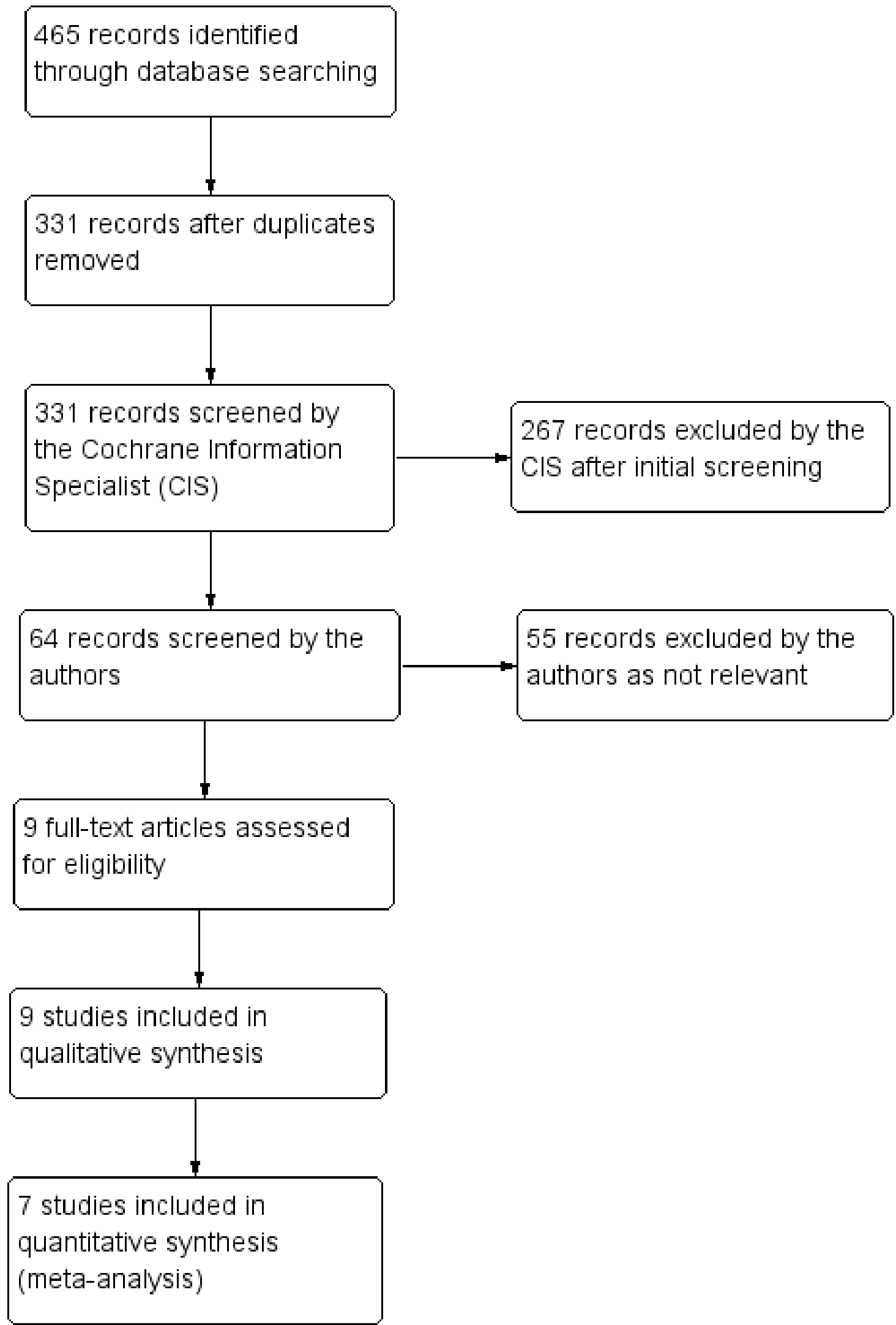




\section{Included studies}

We included nine studies in this review (Alberti 2001; Brahma 1996; Donnenfeld 1995; Goyal 2001; Jayamanne 1997; Kaiser 1997; Patrone 1999; Solomon 2000; Szucs 2000). The interventions compared in this review were diverse (Table 1 ).

\section{Excluded studies}

We did not exclude any study after obtaining the full text of the report.

\section{Risk of bias in included studies}

We evaluated the overall quality of each study according to the methodology detailed in Assessment of risk of bias in included studies. The Characteristics of included studies table presents different 'Risk of bias' domains. Figure 2 and Figure 3 present a graph and summary of the risk of bias of included studies. 
Figure 2. Risk of bias summary: review authors' judgements about each risk of bias item for each included study.

\begin{tabular}{|c|c|c|c|c|c|c|}
\hline & 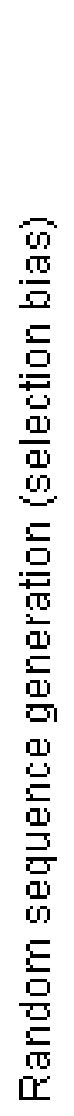 & 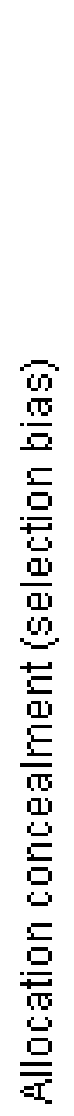 & 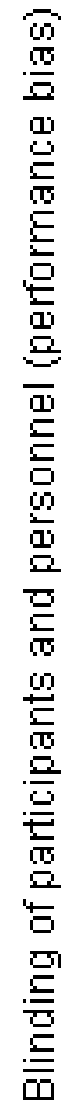 & 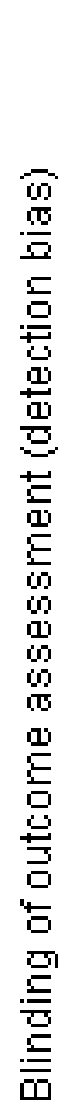 & 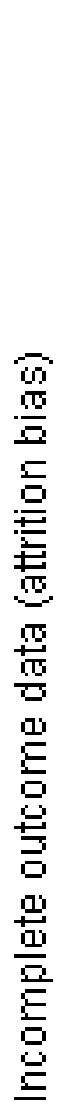 & 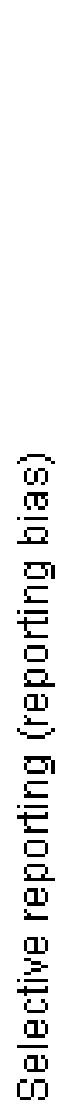 \\
\hline Alberti 2001 & + & $?$ & 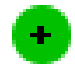 & $?$ & & $?$ \\
\hline Brahma 1996 & & $?$ & $?$ & $?$ & & $?$ \\
\hline Donnenfeld 1995 & & $?$ & & & & $?$ \\
\hline Goyal 2001 & $?$ & $?$ & & + & & $?$ \\
\hline Jayamanne 1997 & $?$ & $?$ & & + & & $?$ \\
\hline Kaiser 1997 & $?$ & + & & $?$ & & ? \\
\hline Patrone 1999 & $?$ & $?$ & $?$ & $?$ & & $?$ \\
\hline Solomon 2000 & $?$ & $?$ & & & & $?$ \\
\hline Szucs 2000 & + & $?$ & + & + & & $?$ \\
\hline
\end{tabular}


Figure 3. Risk of bias graph: review authors' judgements about each risk of bias item presented as percentages across all included studies.

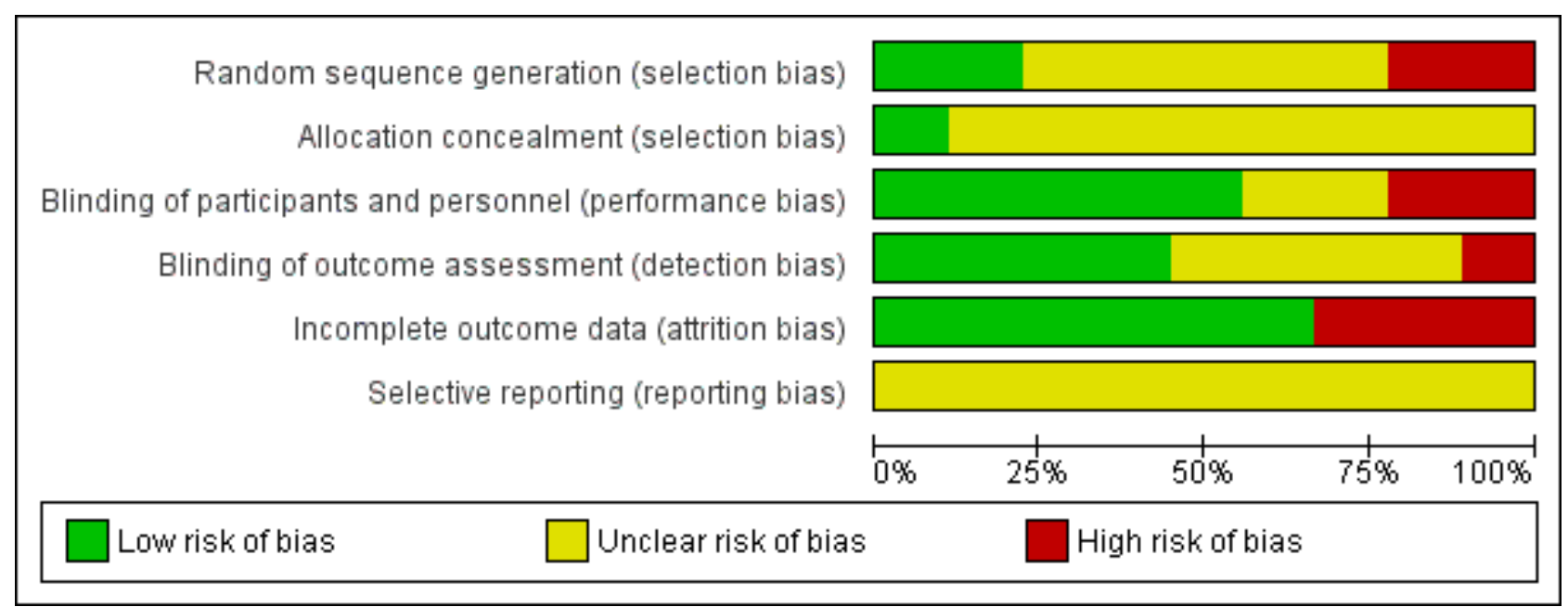

\section{Allocation}

\section{Random sequence generation}

Two of the studies (Brahma 1996; Donnenfeld 1995) were at a high risk of bias due to an inadequate method of sequence generation. We rated five of the studies at an unclear risk, since there was no explicit statement about the method for sequence generation.

\section{Allocation concealment}

Eight of the studies had an unclear risk of bias because there was no explicit statement about allocation concealment.

\section{Blinding}

\section{Performance bias}

In one study, the nature of the interventions was such that double-masking was not feasible (Solomon 2000). In two of the included studies, there was no explicit statement about masking of participants or study personnel (Brahma 1996; Patrone 1999).

\section{Detection bias}

There was a high risk of detection bias in one of the studies (Donnenfeld 1995). In four of the included studies there was a low risk of bias (Goyal 2001; Jayamanne 1997; Solomon 2000; Szucs 2000). The risk of detection bias was unclear in four studies because no explicit statement about masking of outcome assessors was reported (Alberti 2001; Brahma 1996; Kaiser 1997; Patrone 1999).

\section{Incomplete outcome data}

Three of the included studies had a high risk of attrition bias (Brahma 1996; Patrone 1999; Solomon 2000).

\section{Selective reporting}

We judged all studies to have an unclear risk, since no protocol or trial registry entry was available and it was therefore not possible to assess this domain.

\section{Other potential sources of bias}

We did not identify any other potential sources of bias.

Given the relatively small number of included trials, we were unable to assess publication bias (Higgins 2011).

\section{Effects of interventions}

See: Summary of findings for the main comparison Topical NSAIDs compared to control for analgesia in traumatic corneal abrasions

\section{Primary outcome measures}

None of the included studies reported the primary outcome measures of this review (participant-reported pain intensity reduction of $30 \%$ or more at 24 hours and participant-reported pain intensity reduction of $50 \%$ or more at 24 hours).

\section{Secondary outcome measures}

Use of 'rescue' analgesia (that is, oral analgesia) at 24 hours, 48 hours and 72 hours

Four studies reported 'rescue' analgesia at 24 hours as an outcome measure (Alberti 2001; Brahma 1996; Goyal 2001;Szucs 2000) (participants reported $=481$ ). Although these studies employed different comparators (Table 1), we pooled the data, since the treatment effect was in the same direction and the results were consistent. Participants taking NSAIDs were less likely to require rescue analgesia (low-certainty evidence); (risk ratio (RR) 0.46, 95\% confidence interval (Cl) 0.34 to 0.61 ; Analysis 1.1; Figure 4). 
Figure 4. Forest plot of comparison: 1 Topical NSAIDs versus placebo/standard care, outcome: 1.1 Use of rescue oral analgesia at 24 hours.

\begin{tabular}{|c|c|c|c|c|c|}
\hline \multirow[b]{2}{*}{ Study or Subgroup } & \multicolumn{2}{|c|}{ Topical NSAID } & \multicolumn{2}{|c|}{ Control } & \multirow[b]{2}{*}{ Weight } \\
\hline & Events & Total & Events & Total & \\
\hline Alberti 2001 & 4 & 62 & 4 & 61 & $4.7 \%$ \\
\hline Brahma 1996 & 29 & 109 & 66 & 115 & $69.7 \%$ \\
\hline Goyal 2001 & 7 & 43 & 21 & 42 & $15.4 \%$ \\
\hline Szucs 2000 & 5 & 25 & 10 & 24 & $10.1 \%$ \\
\hline Total $(95 \% \mathrm{Cl})$ & & 239 & & 242 & $100.0 \%$ \\
\hline Total events & 45 & & 101 & & \\
\hline $\begin{array}{l}\text { Heterogeneity: Tau }{ }^{2} \\
\text { Test for overall effec }\end{array}$ & $\begin{array}{l}0.00 ; \mathrm{Chi}^{2} \\
z=5.27(\end{array}$ & $\begin{array}{l}=2.08,0 \\
=0.000\end{array}$ & $\begin{array}{l}d f=3(P= \\
001)\end{array}$ & 0.56 & $1^{2}=0 \%$ \\
\hline
\end{tabular}

Risk Ratio Risk Ratio

H, Random, $95 \% \mathrm{Cl}$

Random, $95 \% \mathrm{Cl}$

None of the included studies reported 'rescue' analgesia at 48 hours or at 72 hours as an outcome measure.

\section{Percentage/proportion healed after 24 and 48 hours (healing should have been ascertained using fluorescein staining or slit- lamp examination)}

One study reported the proportion of corneal abrasions that were healed after 24 and 48 hours (Solomon 2000) (participants reported $=28$ ). Ninety-three per cent of abrasions were healed within 24 hours and the remainder within 48 hours. There was no difference in the proportion of abrasions healed between groups (low-certainty evidence); 24 hours (RR $1.00,95 \% \mathrm{Cl} 0.81$ to 1.23 ); 48 hours (RR 1.00, $95 \% \mathrm{Cl} 0.88$ to 1.14; Analysis 1.2 and Analysis 1.3).

\section{Complications of corneal abrasion (as defined by the study authors)}

Six of the studies reported complications of corneal abrasion as an outcome measure (Alberti 2001; Brahma 1996; Goyal 2001; Jayamanne 1997; Kaiser 1997; Szucs 2000) (participants reported = 609). Four of these studies (Brahma 1996; Goyal 2001; Jayamanne 1997; Szucs 2000) reported no complications in either study arm. One study (Alberti 2001) reported a corneal abscess in the comparator group and one study (Kaiser 1997) reported that three participants returned with a recurrent corneal erosion (two in the control group and one in the NSAID group) (very low-certainty evidence); (RR $0.44,95 \% \mathrm{Cl} 0.07$ to 2.96 ; Analysis 1.4).

\section{Whether the use of concurrent topical antibiotics with additional lubricating effects reduced pain}

None of the studies reported whether use of concurrent topical antibiotics (drops or ointments) with additional lubricating effects reduced pain.

\section{Drug-related adverse events}

Two studies reported on drug-related adverse events as an outcome measure (Alberti 2001; Jayamanne 1997) (participants reported $=163$ ). Jayamanne 1997 reported no drug-related events, while Alberti 2001 reported four events (three in the NSAID group, including discomfort/photophobia on instillation, conjunctival hyperaemia and urticaria and one in the control group, corneal abscess) very low-certainty evidence; (RR $2.9595 \% \mathrm{Cl} 0.32$ to 27.60 ; Analysis 1.5).

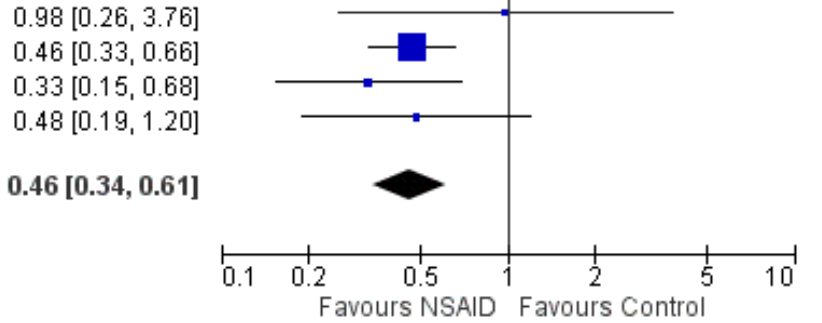

Other adverse events (as defined by the study authors)

None of the nine included studies reported other adverse events as an outcome measure.

\section{DISCUSSION}

\section{Summary of main results}

None of the included studies reported the primary outcome measures of this review, namely participant-reported pain intensity reduction of $30 \%$ or more or of $50 \%$ or more at 24 hours. A $30 \%$ reduction in pain intensity represents a clinically important difference in pain severity that corresponds to patients' perception of adequate pain control (Lee 2003; Younger 2009).

Four trials that randomised 664 participants (481 reported) to receive NSAIDs or placebo/standard care reported on the use of 'rescue' analgesia at 24 hours as a proxy measure of pain control. These trials were associated with a reduction in the need for oral analgesia (RR $0.46,95 \% \mathrm{Cl} 0.34$ to 0.61 ).

One trial, in which 28 participants were randomised, reported on the proportion of abrasions healed after 24 and 48 hours. These levels were similar between both arms of the trial.

Two trials (163 participants randomised) reported on drug-related adverse events, with rates low and similar between the intervention and control groups.

\section{Overall completeness and applicability of evidence}

The review has revealed a lack of high-quality evidence to support the use of topical NSAIDs in traumatic corneal abrasion.

\section{Quality of the evidence}

Despite seven of the nine included studies being conducted following the publication of the CONSORT statement in 1996, the trials were generally poorly reported. Allocation concealment was unclear and in the absence of a protocol or trial registration it was not possible to assess reporting bias. Several of the trials were associated with missing outcome data that were sufficient to have a clinically relevant impact on the effect estimate.

\section{Potential biases in the review process}

As far as we are aware, we have minimised potential biases in the review process. We followed all methods set out in the published protocol and all potentially eligible studies were 
included. Assessment or risk of bias was limited by poor reporting and the absence of published protocols or trial registration.

\section{Agreements and disagreements with other studies or reviews}

A previous systematic review of topical NSAIDs for corneal abrasions (Calder 2005) included 11 RCTs, of which three were included in a meta-analysis of self-reported pain scores at 24 hours. NSAIDs were found to reduce self-reported pain (weighted mean difference (WMD) $-1.3(95 \% \mathrm{Cl}-1.03$ to 1.56$))$. The authors of this review concluded that topical NSAIDs can provide effective analgesia for people with traumatic corneal abrasions.

\section{AUTHORS' CONCLUSIONS}

\section{Implications for practice}

Traumatic corneal abrasions are a common presentation in both general emergency departments and specialist eye units. However there remains a lack of high-quality evidence to inform the management of this condition. Prophylactic antibiotics with or without cycloplegia are typically used, although based on the results of a previous Cochrane Review (Lim 2016) eye patching is no longer recommended. Most simple traumatic abrasions heal within one or two days, but during this period they can be associated with significant pain, foreign body sensation and photophobia. It has been suggested that topical NSAIDs may be used to provide effective analgesia, which could potentially reduce the requirement for oral analgesia, although there have been some concerns in the literature regarding possible impairment of corneal wound healing and drug-induced adverse reactions.

The findings from the trials included in this review do not provide strong evidence to support the use of topical NSAIDs in traumatic corneal abrasions. This is important, since topical NSAIDs are associated with a higher cost compared to oral analgesics. None of the trials addressed our primary outcome measure of participantreported pain intensity reduction of $30 \%$ or more or $50 \%$ or more at 24 hours.

Although there was some evidence from four trials that the use of topical NSAIDs led to a reduced need for 'rescue' analgesia at 24 hours, this finding should be interpreted with caution, since the certainty of the evidence was low.

\section{Implications for research}

Investigators planning future trials on the effectiveness of topical NSAIDs for corneal abrasions should attempt to address the sources of bias identified in the studies included in this review; specifically the use of appropriate methods for randomisation and allocation concealment. Furthermore, strategies should be developed to improve collection of outcome data and reduce attrition bias. Although the use of unidimensional visual analogue scales (VASs) has been shown to be a valid and reproducible method in studies evaluating pain relief, investigators may be tempted to overestimate the clinical importance of small differences in VAS scores. Further work in this context should attempt to determine the minimum clinically important difference as measured by VAS pain scores that represents small, moderate, or large treatment effects.

\section{ACKN OWLEDGEMENTS}

Cochrane Eyes and Vision (CEV) created and executed the electronic search strategies. We acknowledge the help of Dr. Aileen McCabe and Dr. Jameel Awan in the development of the protocol of this review. We thank Martina Bösch, Catey Bunce and Seema Verma for their comments on the protocol or review or both. We thank Jennifer Evans for her guidance on the review and Anupa Shah for her assistance throughout the review process. 


\section{R E F E R E N C E S}

\section{References to studies included in this review}

Alberti 2001 \{published data only\}

Alberti MM, Bouat CG, Allaire CM, Trinquand CJ. Combined indomethacin/gentamicin eyedrops to reduce pain after traumatic corneal abrasion. European Journal of Ophthalmology 2001;11(3):233-9.

\section{Brahma 1996 \{published data only\}}

Brahma AK, Shah S, Hillier VF, McLeod D, Sabala T, Brown A, et al. Topical analgesia for superficial corneal injuries. Journal of Accident and Emergency Medicine 1996;13(3):186-8.

\section{Donnenfeld 1995 \{published data only\}}

Donnenfeld ED, Selkin BA, Perry HD, Moadel K, Selkin GT, Cohen AJ, et al. Controlled evaluation of a bandage contact lens and a topical nonsteroidal anti-inflammatory drug in treating traumatic corneal abrasions. Ophthalmology 1995;102(6):979-84.

\section{Goyal 2001 \{published data only\}}

Goyal R, Shankar J, Fone DL, Hughes DS. Randomised controlled trial of ketorolac in the management of corneal abrasions. Acta Ophthalmologica Scandinavica 2001;79(2):177-9.

\section{Jayamanne 1997 \{published data only\}}

Jayamanne DG, Fitt AW, Dayan M, Andrews RM, Mitchell KW, Griffiths PG. The effectiveness of topical diclofenac in relieving discomfort following traumatic corneal abrasions. Eye 1997;11(Pt 1):79-83.

\section{Kaiser 1997 \{published data only\}}

Kaiser PK, Pineda R 2nd. A study of topical nonsteroidal antiinflammatory drops and no pressure patching in the treatment of corneal abrasions. Corneal Abrasion Patching Study Group. Ophthalmology 1997;104(8):1353-9.

\section{Patrone 1999 \{published data only\}}

Patrone G, Sacca SC, Macri A, Rolando M. Evaluation of the analgesic effect of $0.1 \%$ indomethacin solution on corneal abrasions. Ophthalmologica 1999;213(6):350-4.

\section{Solomon 2000 \{published data only\}}

Solomon A, Halpert M, Frucht-Pery J. Comparison of topical indomethacin and eye patching for minor corneal trauma. Annals of Ophthalmology 2000;32(4):316-9.

\section{Szucs 2000 \{published data only\}}

Szucs PA, Nashed AH, Allegra JR, Eskin B. Safety and efficacy of diclofenac ophthalmic solution in the treatment of corneal abrasions. Annals of Emergency Medicine 2000;35(2):131-7.

\section{Additional references}

\section{Calder 2004}

Calder L, Balasubramanian S, Stiell I. Lack of consensus on corneal abrasion management: results of a national survey. CJEM 2004;6(6):402-7.

\section{Calder 2005}

Calder LA, Balasubramanian S, Fergusson D. Topical nonsteroidal anti-inflammatory drugs for corneal abrasions: meta-analysis of randomized trials. Academic Emergency Medicine 2005;12(5):467-73.

\section{Chiapella 1985}

Chiapella P, Rosenthal R. One year in an eye casualty clinic. British Journal of Ophthalmology 1985;69(11):865-70.

\section{Edwards 1987}

Edwards RS. Ophthalmic emergencies in a district general hospital casualty department. British Journal of Ophthalmology 1987;71(12):938-42.

\section{Egger 1997}

Egger M, Davey Smith G, Phillips AN. Meta-analysis: principles and procedures. BMJ 1997;315(7121):1533-7.

\section{Fenton 2001}

Fenton S, Fenton M, Jackson E. An audit of the ophthalmic division of the accident and emergency department of the Royal Victoria Eye and Ear Hospital, Dublin. Irish Medical Journal 2001;94(9):265-6.

\section{Glanville 2006}

Glanville JM, Lefebvre C, Miles JN, Camosso-Stefinovic J. How to identify randomized controlled trials in MEDLINE: ten years on. Journal of the Medical Library Association 2006;94(2):130-6.

\section{GRADEpro 2014 [Computer program]}

GRADE Working Group, McMaster University. GRADEpro GDT. Version accessed 6 January 2017. Hamilton (ON): GRADE Working Group, McMaster University, 2014.

\section{Guidera 2001}

Guidera AC, Luchs JI, Udell IJ. Keratitis, ulceration, and perforation associated with topical nonsteroidal antiinflammatory drugs. Ophthalmology 2001;108(5):936-44.

\section{Harris 2008}

Harris PM. Nonfatal occupational injuries involving the eyes. Bureau of Labor Statistics (US Department of Labor) 2008.

\section{Higgins 2003}

Higgins JPT, Thompson SG, Deeks JD, Altman G. Measuring inconsistency in meta-analysis. BMJ 2003;327(7414):557-60.

\section{Higgins 2011}

Higgins JP, Altman DG, Sterne JAC editor(s). Chapter 8: Assessing risk of bias in included studies. In: Higgins JP, Green S editor(s). Cochrane Handbook for Systematic Reviews of Interventions Version 5.1.0 (updated March 2011). The Cochrane Collaboration, 2011. Available from handbook.cochrane.org.

\section{Lau 1998}

Lau J, loannidis JPA, Schmid CH. Quantitative synthesis in systematic reviews. Systematic Reviews: Synthesis of Best 
Evidence for Health Care Decisions. 1st Edition. Philadelphia: American College of Physicians, 1998:91-101.

\section{Lee 2003}

Lee JS, Hobden E, Stiell IG, Wells GA. Clinically important change in the visual analog scale after adequate pain control. Academic Emergency Medicine 2003;10(10):1128-30.

\section{Lim 2016}

Lim CHL Turner A, Lim BX. Patching for corneal abrasion. Cochrane Database of Systematic Reviews 2016, Issue 7. [DOI: 10.1002/14651858.CD004764.pub3]

\section{Lin 2000}

Lin JC, Rapuano CJ, Laibson PR, Eagle RC, Cohen EJ. Corneal melting associated with use of topical nonsteroidal anti-inflammatory drugs after ocular surgery. Archives of Ophthalmology 2000;118(8):1129-32.

\section{Pharmakakis 2002}

Pharmakakis NM, Katsimpris JM, Melachrinou MP, Koliopoulos JX. Corneal complications following abuse of topical anesthetics. European Journal of Ophthalmology 2002;12(5):373-8.

\section{Review Manager 52014 [Computer program]}

Nordic Cochrane Centre, The Cochrane Collaboration. Review Manager 5 (RevMan 5). Version 5.3. Copenhagen: Nordic Cochrane Centre, The Cochrane Collaboration, 2014.

\section{Sabri 1998}

Sabri K, Pandit JC, Thaller VT, Evans NM, Crocker GR. National survey of corneal abrasion treatment. Eye 1998;12(Pt 2):278-81.

\section{Shields 1991}

Shields T, Sloane PD. A comparison of eye problems in primary care and ophthalmology practices. Family Medicine 1991;23(7):544-6.

\section{CHARACTERISTICS OF STUDIES}

Characteristics of included studies [ordered by study ID]

\section{Thyagarajan 2006}

Thyagarajan SK, Sharma V, Austin S, Lasoye T, Hunter P. An audit of corneal abrasion management following the introduction of local guidelines in an accident and emergency department. Emergency Medicine Journal 2006;23(7):526-9.

\section{Watson 2013}

Watson SL, Lee M-HH, Barker NH. Interventions for recurrent corneal erosions. Cochrane Database of Systematic Reviews 2013, Issue 8. [DOI: 10.1002/14651858.CD001861.pub3]

\section{Weaver 2003}

Weaver CS, Terrell KM. Evidence-based emergency medicine. Update: do ophthalmic nonsteroidal anti-inflammatory drugs reduce the pain associated with simple corneal abrasion without delaying healing?. Annals of Emergency Medicine 2003;41(1):134-40.

\section{Wilson 2004}

Wilson SA, Last A. Management of corneal abrasions. American Family Physician 2004;70(1):123-8.

\section{Yagci 2011}

Yagci A, Bozkurt B, Egrilmez S, Palamar M, Ozturk BT, Pekel H. Topical anesthetic abuse keratopathy: a commonly overlooked health care problem. Cornea 2011;30(5):571-5.

\section{Younger 2009}

Younger J, McCue R, Mackey S. Pain outcomes: a brief review of instruments and techniques. Current pain and headache reports 2009;13(1):39-43.

\section{References to other published versions of this review McCabe 2012}

McCabe A, Awan JA, Walsh CD, Brown MD, Lawrenson JG, Lawrenson AL, et al. Topical non-steroidal anti-inflammatory drugs for analgesia in traumatic corneal abrasions. Cochrane Database of Systematic Reviews 2012, Issue 4. [DOI: 10.1002/14651858.CD009781]

Alberti 2001

Study design: double-masked, randomised controlled trial
Study centre: multicentre (6 sites)
Number randomised: 126
Losses to follow-up: 3
Number analysed: 123
Sample size calculation: not reported

Participants Country: France and Portugal 
Alberti 2001 (Continued)

Age (SD): 38.1 (15.9)

\% Male: $82.1 \%$

Inclusion Criteria: outpatients of either sex, aged over 18 years, with traumatic corneal abrasion or requiring ablation of a superficial corneal foreign body and/or curettage, and in whom the pain due to the lesion was $>20 \mathrm{~mm}$ on a horizontal VAS; $0 \mathrm{~mm}=$ no pain, $100 \mathrm{~mm}=$ unbearable pain

Exclusion criteria: previous intolerance to the tested products or any NSAID or aminoglycoside, local or systemic anti-inflammatory treatment within the 5 days before the initial visit, systemic analgesia within the 24 hours before the initial visit, evolutive ocular pathology, any other concomitant traumatic lesion of the eye, deep corneal lesion, abrasions caused by contact lenses or chemical agents, plant foreign body still present on the cornea at the initial visit, complications of a traumatic corneal lesion requiring any treatment other than the study treatments, and monophthalmia

Intervention: indomethacin $0.1 \% / g e n t a m i c i n$ sulfate $300,000 \mathrm{IU} / 100 \mathrm{~mL}$ eye drops, 4 times daily for 4 - 5
days
Comparator: gentamicin sulfate $300 \mathrm{mg} / 100 \mathrm{~mL}$ eye drops, 4 times daily for 4 - 5 days
Interventions received by both groups: none
Other study arms not included in this review: none
Length of follow-up: 4 - 5 days

Outcomes
Primary outcome(s): pain on a horizontal VAS
Secondary outcome(s): evaluation of associated symptoms (photophobia, tearing, burning, irritation
and foreign body sensation on a $0-3$ scale $(0=$ absent; $I=$ mild; $2=$ moderate; $3=$ severe); conjunctival
hyperaemia and ciliary injection at day 0 , day 1 , and day $4 / 5$ visits using the same 0 - 3 severity scale;
surface area of the corneal abrasion at each visit; use of systemic analgesics

Adverse events reported $(\mathrm{Y} / \mathrm{N}): \mathrm{Y}$

Intervals at which outcome(s) assessed: baseline (T0), one hour after first treatment instillation (T1), one hour after the second treatment instillation on day 0 (T2) and then on day 1 and day 4 or 5

Study dates: January to June 1998
Trial registration: not reported
Funding source(s): Laboratoire Chauvin
Declaration of interest: not reported

\section{Risk of bias}

\begin{tabular}{|c|c|c|}
\hline Bias & Authors' judgement & Support for judgement \\
\hline $\begin{array}{l}\text { Random sequence genera- } \\
\text { tion (selection bias) }\end{array}$ & Low risk & $\begin{array}{l}\text { Quote: "The randomisation list was established using the PROC RANUNI proce- } \\
\text { dure (SAS }{ }^{\circledR} \text { Institute)." p235 }\end{array}$ \\
\hline $\begin{array}{l}\text { Allocation concealment } \\
\text { (selection bias) }\end{array}$ & Unclear risk & $\begin{array}{l}\text { Comment: there is no explicit statement about the method used to conceal al- } \\
\text { location }\end{array}$ \\
\hline $\begin{array}{l}\text { Blinding of participants } \\
\text { and personnel (perfor- } \\
\text { mance bias) } \\
\text { All outcomes }\end{array}$ & Low risk & $\begin{array}{l}\text { Quote: "This was a randomised, double-masked, parallel- group study carried } \\
\text { out from January to June ' } 98 \text { at six centres, in France and Portugal." p234 }\end{array}$ \\
\hline
\end{tabular}


Alberti 2001 (Continued)

Blinding of outcome as- Unclear risk Comment: there is no explicit statement about masking of outcome assesssessment (detection bias) ment

All outcomes

\begin{tabular}{lll}
$\begin{array}{l}\text { Incomplete outcome data } \\
\text { (attrition bias) } \\
\text { All outcomes }\end{array}$ & Low risk & $\begin{array}{l}\text { Comment: }>80 \% \text { follow-up. Reasons for missing data provided and any imbal- } \\
\text { ance unrelated to the outcome }\end{array}$ \\
\hline $\begin{array}{l}\text { Selective reporting (re- } \\
\text { porting bias) }\end{array}$ & Unclear risk & $\begin{array}{l}\text { Comment: no protocol or trial registry entry available and therefore not possi- } \\
\text { ble to assess }\end{array}$ \\
\hline
\end{tabular}

\section{Brahma 1996}

Study design: randomised controlled trial
Study centre: single centre
Number randomised: 401
Losses to follow-up: 177
Number analysed: 224
Sample size calculation: stated that statistical advice was sought to determine sample size for a signifi-
cance level of $5 \%$

Country: UK
Age (SD): 33.7 (SD not reported)
\% Male: $80.6 \%$
Inclusion criteria: participants with corneal abrasions and foreign bodies attending an emergency eye
centre
Exclusion criteria: participants < 16 years; pregnant women; those with a history of herpes simplex ker-
atitis; known hypersensitivity to NSAIDs

Interventions Interventions: flurbiprofen $0.03 \%$ eye drops 4 times daily for 48 hours; homatropine $2 \%$ eye drops at presentation only and flurbiprofen $0.03 \%$ eye drops 4 times daily for 48 hours

Comparators: polyvinyl alcohol 1.4\% (Liquifilm Tears) 4 times daily for 48 hours; homatropine $2 \%$ eye drops at presentation only

Interventions received by all groups: chloramphenicol $1 \%$ eye ointment, 4 times daily for 5 days

Other study arms not included in this review: none

Length of follow-up: 24 hours

Outcomes

Primary outcome(s): ocular pain on a $10-\mathrm{cm}$ linear VAS (where $0=$ no pain and $10=$ worst pain ever experienced)

Secondary outcome(s): oral analgesia ( $\mathrm{Y} / \mathrm{N})$; sleep disturbance (normal/disturbed); time off work due to eye injury

Adverse events reported $(Y / N): Y$

Intervals at which outcome(s) assessed: every 6 hours for 24 hours 
Brahma 1996 (Continued)

Notes
Study dates: August 1993 - December 1993

Trial registration: not reported

Funding source(s): Allergan UK provided study medications

Declaration of interest: "None of the authors has any financial interest in Allergan Therapeutics"

\section{Risk of bias}

\begin{tabular}{|c|c|c|}
\hline Bias & Authors' judgement & Support for judgement \\
\hline $\begin{array}{l}\text { Random sequence genera- } \\
\text { tion (selection bias) }\end{array}$ & High risk & $\begin{array}{l}\text { Quote: "Patients were consecutively allocated at random to one of four treat- } \\
\text { ment groups (table1)". p186 }\end{array}$ \\
\hline $\begin{array}{l}\text { Allocation concealment } \\
\text { (selection bias) }\end{array}$ & Unclear risk & $\begin{array}{l}\text { Comment: there is no explicit statement about the method used to conceal al- } \\
\text { location }\end{array}$ \\
\hline $\begin{array}{l}\text { Blinding of participants } \\
\text { and personnel (perfor- } \\
\text { mance bias) } \\
\text { All outcomes }\end{array}$ & Unclear risk & $\begin{array}{l}\text { Comment: there is no explicit statement about masking of participants and } \\
\text { study personnel }\end{array}$ \\
\hline $\begin{array}{l}\text { Blinding of outcome as- } \\
\text { sessment (detection bias) } \\
\text { All outcomes }\end{array}$ & Unclear risk & Comment: there is no explicit statement about masking of outcome assessors \\
\hline $\begin{array}{l}\text { Incomplete outcome data } \\
\text { (attrition bias) } \\
\text { All outcomes }\end{array}$ & High risk & Comment: high attrition (> 40\%). Missing data likely to bias results \\
\hline $\begin{array}{l}\text { Selective reporting (re- } \\
\text { porting bias) }\end{array}$ & Unclear risk & $\begin{array}{l}\text { Comment: no protocol or trial registry entry available and therefore not possi- } \\
\text { ble to assess }\end{array}$ \\
\hline
\end{tabular}

Donnenfeld 1995

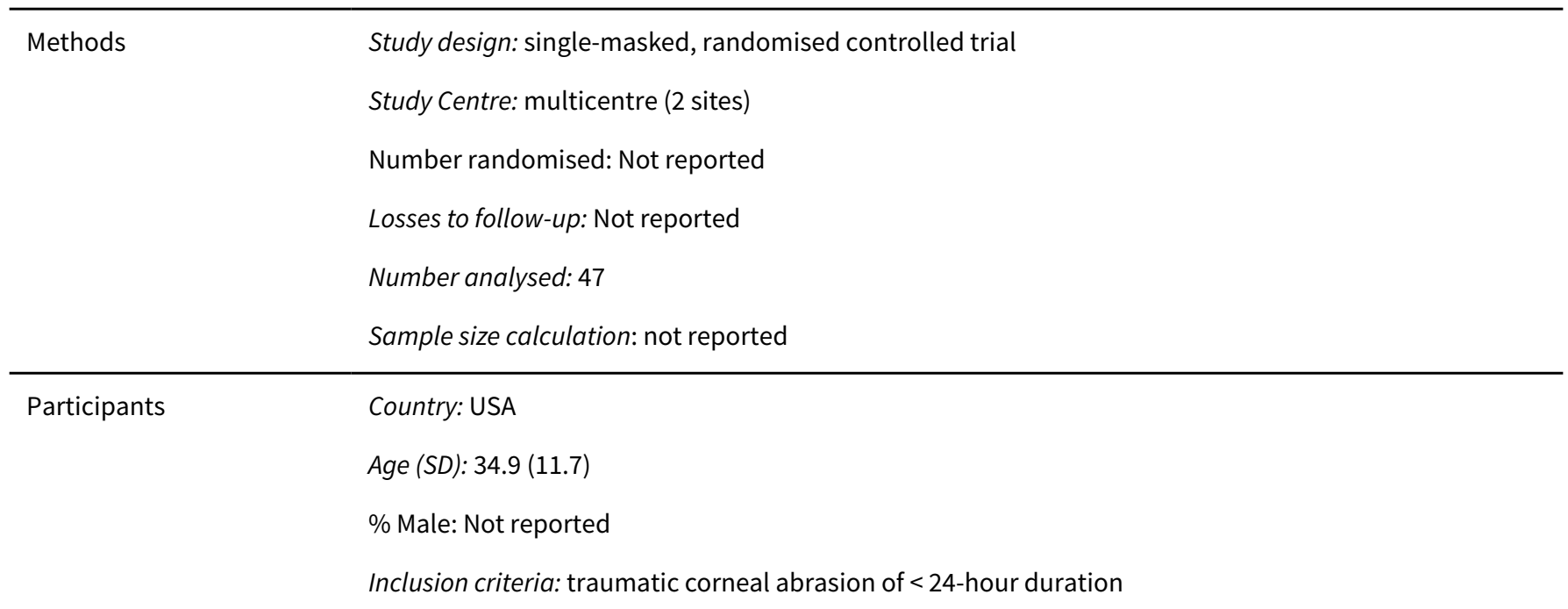


Donnenfeld 1995 (Continued)

Exclusion criteria: monocular vision; a history of wound healing problems (e.g. collagen vascular disease or corticosteroid use); usage of other ocular medications or oral NSAIDs; dry eyes; blepharitis; systemic infections; and contact lens-related epithelial defects

Interventions

Intervention: ketorolac tromethamine $0.5 \%$ eye drops, 4 times daily

Comparator: placebo (Tears Plus), 4 times daily

Interventions received by both groups: bandage contact lens, single instillation of cyclopentolate $1 \%$ eye drops, polymyxin B sulphate/trimethoprim hemisulfate eye drops 4 times daily

Other study arms not included in this review: single instillation of polymyxin B sulphate/ trimethoprim hemisulfate, single instillation of cyclopentolate $1 \%$ and a standard pressure patch

Length of follow-up: 1 - 3 days (until resolution of corneal epithelial defect)

Putcomes
Pecondary outcome $(s)$ : level of pain, photophobia, ocular irritation, redness, headache, tearing; ability
to return to normal activities
Adverse events reported $(\mathrm{Y} / \mathrm{N}): \mathrm{Y}$
Intervals at which outcome $(\mathrm{S})$ assessed: psychometric testing at baseline and follow-up day 1 , corneal
epithelial defect monitored to resolution

Notes

Study dates: June 1993 - April 1994

Trial registration: not reported

Funding source(s): Lions Club International; Allergan Pharmaceuticals

Declaration of interest: not reported

\section{Risk of bias}

\begin{tabular}{lll}
\hline Bias & Authors' judgement & Support for judgement \\
\hline $\begin{array}{l}\text { Random sequence genera- } \\
\text { tion (selection bias) }\end{array}$ & High risk & $\begin{array}{l}\text { Quote: "Patients were assigned randomly to one of three treatment groups." } \mathrm{p} \\
980 .\end{array}$ \\
& $\begin{array}{l}\text { Comment: there are no details on the method of randomisation. Although par- } \\
\text { ticipants were "randomly assigned" to } 1 \text { of } 3 \text { groups, from the results table, } \\
\text { the randomisation seemed to be highly predictable, i.e. case numbers in each } \\
\text { group were separated by } 3\end{array}$
\end{tabular}

\begin{tabular}{|c|c|c|}
\hline $\begin{array}{l}\text { Allocation concealment } \\
\text { (selection bias) }\end{array}$ & Unclear risk & $\begin{array}{l}\text { Comment: there is no explicit statement about the method used to conceal al- } \\
\text { location }\end{array}$ \\
\hline
\end{tabular}

Blinding of participants High risk
and personnel (perforQuote: "This was done in a single-masked randomised fashion. The patients in mance bias)

All outcomes groups $B$ and $C$ were instructed to administer a drop of both the polymyxin B sulfate/trimethoprim sulfate and the contents of the masked bottle four times daily, 5 minutes apart." p 980.

Comment: study described as 'single masked' and study personnel were unmasked

\begin{tabular}{lll}
\hline Blinding of outcome as- & High risk & Quote: "Forty-seven consecutive patients with traumatic corneal abrasions \\
sessment (detection bias) & & were randomised prospectively in a single-masked, controlled clinical trial ..." \\
All outcomes & p 980.
\end{tabular}




\begin{tabular}{lll}
\hline $\begin{array}{l}\text { Incomplete outcome data } \\
\text { (attrition bias) } \\
\text { All outcomes }\end{array}$ & Low risk \\
\hline $\begin{array}{l}\text { Selective reporting (re- } \\
\text { porting bias) }\end{array}$ & Unclear risk & $\begin{array}{l}\text { Comment: no protocol or trial registry entry available and therefore not possi- } \\
\text { ble to assess }\end{array}$ \\
\hline
\end{tabular}

Goyal 2001

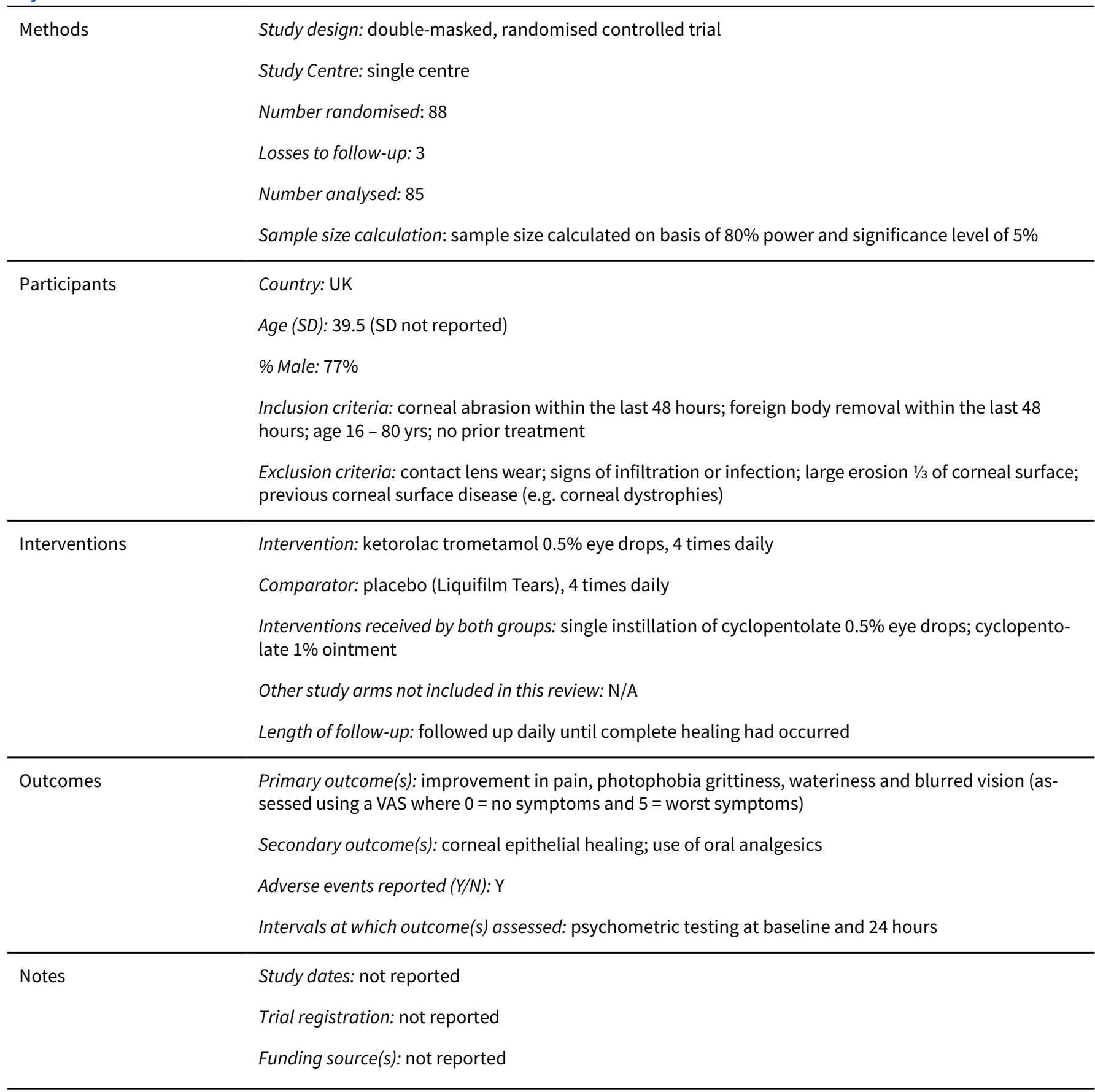


Goyal 2001 (Continued)

Declaration of interest: not reported

\section{Risk of bias}

Bias Authors' judgement Support for judgement

Random sequence genera- Unclear risk Comment: no explicit statement about the method of randomisation
tion (selection bias)

\begin{tabular}{|c|c|c|}
\hline $\begin{array}{l}\text { Allocation concealment } \\
\text { (selection bias) }\end{array}$ & Unclear risk & $\begin{array}{l}\text { Comment: there is no explicit statement about the method used to conceal al- } \\
\text { location }\end{array}$ \\
\hline
\end{tabular}

$\begin{aligned} & \text { Blinding of participants } \\ & \begin{array}{l}\text { and personnel (perfor- } \\ \text { mance bias) }\end{array}\end{aligned}$
$\begin{aligned} & \text { All outcomes } \\ & \text { ture of the drops." p } 177 .\end{aligned}$

\begin{tabular}{lll}
\hline $\begin{array}{l}\text { Blinding of outcome as- } \\
\begin{array}{l}\text { sessment (detection bias) } \\
\text { All outcomes }\end{array}\end{array}$ & Low risk & $\begin{array}{l}\text { Quote: "Neither the examining doctor nor the patient was aware as to the na- } \\
\text { ture of the drops." p } 177 .\end{array}$ \\
\hline $\begin{array}{l}\text { Incomplete outcome data } \\
\text { (attrition bias) }\end{array}$ & Low risk & $\begin{array}{l}\text { Quote: "Eighty-eight patients were enrolled in the study. Three were excluded } \\
\text { as they either did not fulfil the eligibility criteria or had failed to attend for fol- } \\
\text { low [up]." p } 177 .\end{array}$ \\
\hline $\begin{array}{l}\text { Selective reporting (re- } \\
\text { porting bias) }\end{array}$ & Unclear risk & $\begin{array}{l}\text { Comment: > } 95 \% \text { of participants completed the study } \\
\text { ble to assess }\end{array}$ \\
\hline
\end{tabular}

\section{Jayamanne 1997}

Study design: double-masked, randomised controlled trial
Study centre: single centre
Number randomised: 40
Losses to follow-up: 0
Number analysed: 40
Sample size calculation: not reported
Country: UK
Age (SD): not reported
\% Male: not reported
Inclusion criteria: participants aged > 18 years presenting within 24 hours of a unilateral corneal abra-
sion and no other injury
$\begin{aligned} & \text { Exclusion criteria: previous corneal pathology, including dystrophies and recurrent erosion syndrome, } \\ & \text { diabetes, those under } 18 \text { years of age or with known hypersensitivity to either NSAIDs or chlorampheni- } \\ & \text { col }\end{aligned}$


Jayamanne 1997 (Continued)

Comparator: normal saline eye drop 4 times daily in the affected eye

Interventions received by both groups: chloramphenicol eye ointment

Other study arms not included in this review: none

Length of follow-up: until complete healing had occurred (all healed within 96 hours)

Primary outcome(s): pain measured with a VAS (a horizontal line measuring $10 \mathrm{~cm}$ in length showing a
continuum from "no pain" to "worst pain ever"); categorical scale (none, mild discomfort not requiring
painkillers, moderate pain requiring painkillers or severe disabling pain); and sub-categorisation into
foreign body sensation, light sensitivity and headache-like deep pain within the eye and rating for the
sub-categories as none, mild, moderate or severe
Secondary outcome $(\mathrm{s})$ : none
Adverse events reported $(\mathrm{Y} / \mathrm{N}): \mathrm{Y}$
Intervals at which outcome $(\mathrm{S})$ assessed: baseline (day 0$)$, day 1 , day 2
Study dates: not reported
Trial registration: not reported
Funding source(s): not reported
Declaration of interest: not reported

\section{Risk of bias}

\begin{tabular}{|c|c|c|}
\hline Bias & Authors' judgement & Support for judgement \\
\hline \multirow[t]{2}{*}{$\begin{array}{l}\text { Random sequence genera- } \\
\text { tion (selection bias) }\end{array}$} & Unclear risk & $\begin{array}{l}\text { Quote: "Patients were randomly assigned to one of two treatment groups." p } \\
79 .\end{array}$ \\
\hline & & Comment: there is no explicit statement about the method of randomisation \\
\hline $\begin{array}{l}\text { Allocation concealment } \\
\text { (selection bias) }\end{array}$ & Unclear risk & $\begin{array}{l}\text { Comment: there is no explicit statement about the method used to conceal al- } \\
\text { location }\end{array}$ \\
\hline $\begin{array}{l}\text { Blinding of participants } \\
\text { and personnel (perfor- } \\
\text { mance bias) } \\
\text { All outcomes }\end{array}$ & Low risk & Quote: "The drops were dispensed in unmarked containers." p 79. \\
\hline
\end{tabular}

\begin{tabular}{|c|c|c|}
\hline $\begin{array}{l}\text { Blinding of outcome as- } \\
\text { sessment (detection bias) } \\
\text { All outcomes }\end{array}$ & Low risk & $\begin{array}{l}\text { Quote: "Doctors involved in the patient assessments were masked as to the } \\
\text { study drug codes." p } 80 . \\
\text { Quote: "...no unmasking of patients occurred during the trial." p } 80 .\end{array}$ \\
\hline $\begin{array}{l}\text { Incomplete outcome data } \\
\text { (attrition bias) } \\
\text { All outcomes }\end{array}$ & Low risk & Quote: "All patients completed the study as planned...". p 80 \\
\hline $\begin{array}{l}\text { Selective reporting (re- } \\
\text { porting bias) }\end{array}$ & Unclear risk & $\begin{array}{l}\text { Comment: no protocol or trial registry entry available and therefore not possi- } \\
\text { ble to assess }\end{array}$ \\
\hline
\end{tabular}


Kaiser 1997

Methods
Study design: double-masked, randomised controlled trial.

Study centre: single centre

Number randomised: not reported (100 enrolled)

Losses to follow-up: not reported (12 failed to complete due to ineligibility or loss to follow-up)

Number analysed: 88

Sample size calculation: not reported

Intervention: ketorolac tromethamine $0.5 \%$ ophthalmic solution 4 times daily
Comparator: control vehicle drops 4 times daily
Interventions received by both groups: cycloplegic drops (cyclopentolate $1 \% /$ phenylephrine $2.5 \% /$
tropicamide $0.25 \%$ ) and erythromycin or polymyxin B (Polysporin) ophthalmic ointment
Other study arms not included in this review: none
Length of follow-up: not reported

Outcomes Primary outcome(s): subjective symptoms: photophobia, tearing, foreign body sensation, and "blurry vision"; level of pain assessed on a scale of $0-10$, with 0 representing no pain and 10 representing severe pain

Secondary outcome(s): ability to return to normal activities

Adverse events reported $(Y / N): Y$

Intervals at which outcome(s) assessed: baseline (day 0), day 1 , day 2

\begin{tabular}{l}
\hline Study dates: not reported \\
Trial registration: not reported \\
Funding source(s): not reported \\
Declaration of interest: not reported
\end{tabular}

\section{Risk of bias}

\begin{tabular}{lll}
\hline Bias & Authors' judgement & Support for judgement \\
\hline $\begin{array}{ll}\text { Random sequence genera- } \\
\text { tion (selection bias) }\end{array}$ & Unclear risk & $\begin{array}{l}\text { Quote: "Patients were randomly assigned in the eye emergency ward by the } \\
\text { treating physician, who obtained an ocular medication bottle marked "A" or } \\
\text { "B." p } 1354 \\
\end{array}$ \\
& Comment: there is no explicit statement about the method of randomisation \\
\hline \hline
\end{tabular}


Kaiser 1997 (Continued)

$\begin{aligned} & \text { Allocation concealment } \\ & \text { (selection bias) }\end{aligned} \quad$ Low risk
who did not enrol patients in the study." p 1354

Blinding of participants Low risk and personnel (perfor-

Quote: "Both the physician and the patient were unaware of which bottle conmance bias)

All outcomes

\section{Blinding of outcome as-} sessment (detection bias)

Unclear risk tained the ketorolac tromethamine $0.5 \%$ ophthalmic solution." p 1354

\begin{tabular}{lll}
\hline $\begin{array}{l}\text { Incomplete outcome data } \\
\text { (attrition bias) } \\
\text { All outcomes }\end{array}$ & Low risk \\
\hline $\begin{array}{l}\text { Selective reporting (re- } \\
\text { porting bias) }\end{array}$ & Unclear risk & $\begin{array}{l}\text { Comment: no protocol or trial registry entry available and therefore not possi- } \\
\text { ble to assess }\end{array}$
\end{tabular}

\title{
Patrone 1999
}

\section{Methods}

\author{
Study design: randomised controlled trial \\ Study centre: single centre \\ Number randomised: 409 \\ Losses to follow-up: 62 \\ Number analysed: 347 \\ Sample size calculation:not reported
}

Country: Italy
Age (SD): $43.4(15.7)$
\% Male: $66.5 \%$
Inclusion criteria: corneal abrasion < $16 \mathrm{~mm}^{2}$; no limbus and/or ocular structure involvement; occurred
less than 12 hours before the clinical examination; no chronic ocular pathology or systemic pathologies
or neurological/corneal pathologies able to influence corneal sensitivity; absence of corneal sensitivity
impairments to the contralateral undamaged eye

Exclusion criteria: participants with abrasions caused by thermal, radiant or caustic agents; contact lens-wearing participants; and one-eyed or functionally one-eyed participants

\begin{tabular}{ll} 
Interventions & Intervention: indomethacin $0.1 \%$ eye drops; netilmicin $0.3 \%$ every 4 hours \\
Comparator: $0.3 \%$ netilmicin only every 4 hours \\
Interventions received by both groups: bandage contact lens for 24 hours \\
Other study arms not included in this review: N/A \\
Length of follow-up: not recorded (monitored daily until healing of corneal abrasion) \\
\hline Primary outcome(s): Subjective pain was evaluated using a VPS \\
Secondary outcome(s): none
\end{tabular}


Patrone 1999 (Continued)

\section{Adverse events reported $(Y / N): \mathrm{N}$}

Intervals at which outcome(s) assessed: 30 mins after the first medication (T0); during the first check-up (after 12 hours; T1), and during the second check-up (after 24 hours; T2)

Study dates: January 1994 - February 1997
Trial registration: not reported
Funding source(s): not reported
Declaration of interest: "The authors have no proprietary or financial interest in the development or
marketing of this or any competing drug."

\section{Risk of bias}

\begin{tabular}{|c|c|c|}
\hline Bias & Authors' judgement & Support for judgement \\
\hline \multirow[t]{2}{*}{$\begin{array}{l}\text { Random sequence genera- } \\
\text { tion (selection bias) }\end{array}$} & Unclear risk & $\begin{array}{l}\text { Quote: "The protocol randomised the patients into two homogeneous } \\
\text { groups." p } 351\end{array}$ \\
\hline & & $\begin{array}{l}\text { Comment: there is no explicit statement about the method used for randomi- } \\
\text { sation }\end{array}$ \\
\hline $\begin{array}{l}\text { Allocation concealment } \\
\text { (selection bias) }\end{array}$ & Unclear risk & Comment: there is no explicit description about allocation concealment \\
\hline $\begin{array}{l}\text { Blinding of participants } \\
\text { and personnel (perfor- } \\
\text { mance bias) } \\
\text { All outcomes }\end{array}$ & Unclear risk & Comment: there is no explicit statement about masking of study participants \\
\hline $\begin{array}{l}\text { Blinding of outcome as- } \\
\text { sessment (detection bias) } \\
\text { All outcomes }\end{array}$ & Unclear risk & Comment: there is no explicit statement about masking of outcome assessors \\
\hline \multirow{2}{*}{$\begin{array}{l}\text { Incomplete outcome data } \\
\text { (attrition bias) } \\
\text { All outcomes }\end{array}$} & High risk & $\begin{array}{l}\text { Quote: "Of the } 409 \text { patients who joined the study, } 62 \text { were excluded because } \\
\text { they failed to respect the instructions of the protocol." p } 352\end{array}$ \\
\hline & & $\begin{array}{l}\text { Comment: there were no data on the outcomes of the } 62 \text { excluded participants } \\
\text { or reasons for dropout }\end{array}$ \\
\hline $\begin{array}{l}\text { Selective reporting (re- } \\
\text { porting bias) }\end{array}$ & Unclear risk & $\begin{array}{l}\text { Comment: no protocol or trial registry entry available and therefore not possi- } \\
\text { ble to assess }\end{array}$ \\
\hline
\end{tabular}

\section{Solomon 2000}

Study design: randomised controlled trial
Study centre: single centre
Number randomised: 28
Losses to follow-up: 0
Number analysed: 28
Sample size calculation: not reported


Solomon 2000 (Continued)

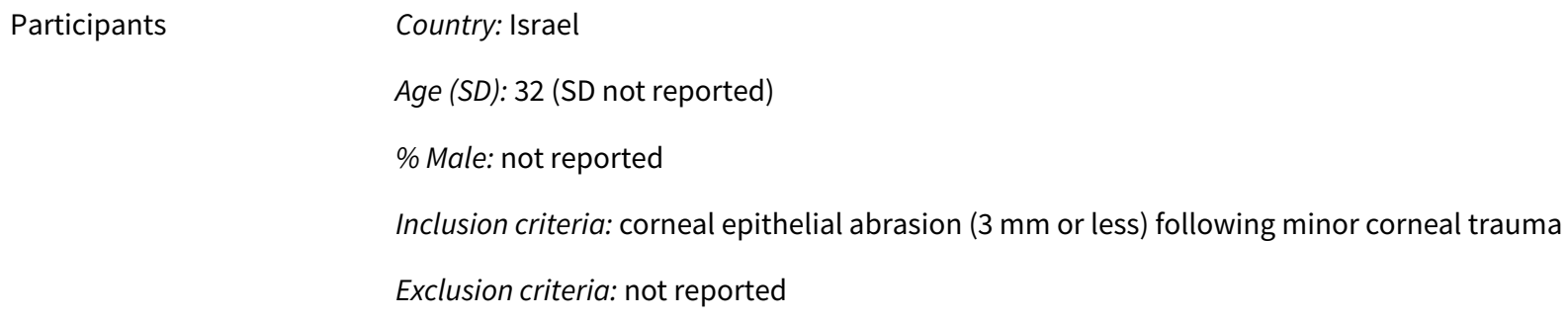

Outcomes

Primary outcome(s): pain, graded on a scale of 0 - 10; other symptoms including tearing, itching, burning, discharge, foreign body sensation, and photophobia graded on a scale from 0 - 3

Secondary outcome(s): objective signs including swelling or hyperaemia of the eyelid and conjunctival hyperaemia evaluated on a scale of 0 - 3 ; healing of corneal abrasion

\section{Adverse events reported $(\mathrm{Y} / \mathrm{N}): \mathrm{N}$}

Intervals at which outcome(s) assessed: 6 - 9 hours after start of treatment follow-up 18 - 24 hours after the first visit

\begin{tabular}{ll}
\hline Notes & Study dates: not reported \\
& Trial registration: not reported \\
Funding source(s): not reported \\
Declaration of interest: not reported \\
\hline
\end{tabular}

\section{Risk of bias}

\begin{tabular}{|c|c|c|}
\hline Bias & Authors' judgement & Support for judgement \\
\hline \multirow[t]{2}{*}{$\begin{array}{l}\text { Random sequence genera- } \\
\text { tion (selection bias) }\end{array}$} & Unclear risk & $\begin{array}{l}\text { Quote: "Patients were randomly assigned into } 1 \text { of } 2 \text { treatment protocols." p } \\
317\end{array}$ \\
\hline & & Comment: there is no explicit statement about the method of randomisation \\
\hline $\begin{array}{l}\text { Allocation concealment } \\
\text { (selection bias) }\end{array}$ & Unclear risk & Comment: there is no explicit statement about the allocation concealment \\
\hline $\begin{array}{l}\text { Blinding of participants } \\
\text { and personnel (perfor- } \\
\text { mance bias) } \\
\text { All outcomes }\end{array}$ & High risk & $\begin{array}{l}\text { Comment: the nature of the comparator interventions were such that masking } \\
\text { was not feasible }\end{array}$ \\
\hline $\begin{array}{l}\text { Blinding of outcome as- } \\
\text { sessment (detection bias) } \\
\text { All outcomes }\end{array}$ & Low risk & $\begin{array}{l}\text { Quote: "The first eye examination was always performed by } 1 \text { of the authors } \\
\text { (M.H.), whereas the follow-up examination was done by another author (J.F.- } \\
\text { P.), who was unaware of the treatment used." p } 317\end{array}$ \\
\hline
\end{tabular}


Solomon 2000 (Continued)

Incomplete outcome data High risk (attrition bias)

All outcomes
Quote: "After 6 to 9 hours, we recorded symptoms in 10 of the 14 patients in group 1 and 11 of the 14 patients in group 2; the other patients were not available." p 317

Comment: > 20\% attrition for assessment at 9 hours, which may have biased results

$\begin{array}{lll}\begin{array}{l}\text { Selective reporting (re- } \\ \text { porting bias) }\end{array} & \text { Unclear risk } & \begin{array}{l}\text { Comment: no protocol or trial registry entry and therefore not possible to as- } \\ \text { sess }\end{array}\end{array}$

Szucs 2000

Study design: double-masked, randomised controlled trial
Study centre: single centre
Number randomised: 49
Losses to follow-up: 0
Number analysed: 49
Sample size calculation: stated that sample size calculation was performed to determine the number of
participants for a specified outcome
Country: USA
Age (SD): 39.5 (SD not reported)
\% Male: $73 \%$
Inclusion criteria: aged 18 years or older with a traumatic corneal abrasion
Exclusion criteria: history of recent eye surgery, glaucoma, ocular infection, other signs of ocular trau-
ma; adverse reactions to diclofenac or NSAIDs including aspirin; any narcotic use within 6 hours of ED
treatment; unavailable for telephone follow-up at 2 hours; minimal pain defined as a score of 3 or less
on the NPIS; pregnancy, women of childbearing age in whom pregnancy could not be excluded by his-
tory of last menstrual period, and lactating women

Interventions

Intervention: single instillation of diclofenac $0.1 \%$ eye drops in the ED and then every 6 hours for 24 - 36 hours

Comparator: control vehicle (Natural Tears)

Interventions received by both groups: single instillation of cyclopentolate $0.5 \%$ eye drops, at the discretion of the treating physician; gentamicin $0.3 \%$ eye drops, every 2 hours for 24 hours

Other study arms not included in this review: N/A

Length of follow-up: 24 hours

Outcomes Primary outcome(s): improvement of pain 2 hours after treatment

Secondary outcome(s): need for rescue oral analgesia

Adverse events reported $(\mathrm{Y} / \mathrm{N}): \mathrm{Y}$

Intervals at which outcome(s) assessed: 2 hours after start of treatment 
Szucs 2000 (Continued)

Trial registration: not reported

Funding source(s): not reported

Declaration of interest: not reported

\section{Risk of bias}

\begin{tabular}{lll}
\hline Bias & Authors' judgement & Support for judgement \\
\hline $\begin{array}{l}\text { Random sequence genera- } \\
\text { tion (selection bias) }\end{array}$ & Low risk & $\begin{array}{l}\text { Quote: "Eligible patients who had corneal abrasions detected by fluorescein } \\
\text { uptake during slit lamp examination who signed consent were then random- } \\
\text { ly assigned by our institution's Pharmacy Investigational and Clinical Ser- } \\
\text { vices using a Ciba-Geigy Scientific Random Number Table to receive either di- } \\
\text { clofenac or control vehicle drops." p } 132\end{array}$ \\
\hline
\end{tabular}

\begin{tabular}{lll}
\hline $\begin{array}{l}\text { Allocation concealment } \\
\text { (selection bias) }\end{array}$ & Unclear risk & Comment: there is no explicit statement about the allocation concealment \\
\hline $\begin{array}{l}\text { Blinding of participants } \\
\begin{array}{l}\text { and personnel (perfor- } \\
\text { mance bias) }\end{array}\end{array}$ & Low risk & $\begin{array}{l}\text { Quote: "Blinding was maintained with the use of identically labelled and } \\
\text { masked bottles. The contents of the bottles were not visible through the mask- } \\
\text { ill outcomes }\end{array}$
\end{tabular}

\begin{tabular}{|c|c|c|}
\hline $\begin{array}{l}\text { Blinding of outcome as- } \\
\text { sessment (detection bias) }\end{array}$ & Low risk & $\begin{array}{l}\text { Quote: "The patient, physician, and nurse remained blinded to the medication } \\
\text { throughout the entire study." p } 133\end{array}$ \\
\hline
\end{tabular}

\begin{tabular}{lll}
\hline $\begin{array}{l}\text { Incomplete outcome data } \\
\text { (attrition bias) }\end{array}$ & Low risk & $\begin{array}{l}\text { Quote: "We did not have complete follow-up for 1 patient who was reexamined } \\
\text { by an ophthalmologist. This patient was ultimately excluded from the study. } \\
\text { Pain scores at 2 hours were obtained for all patients enrolled in the study." } \\
\text { p133 }\end{array}$ \\
\hline $\begin{array}{l}\text { Selective reporting (re- } \\
\text { porting bias) }\end{array}$ & Unclear risk & $\begin{array}{l}\text { Comment: no protocol or trial registry entry and therefore not possible to as- } \\
\text { sess }\end{array}$ \\
\hline
\end{tabular}

ED: emergency department

NPIS: numerical pain intensity score

IU: international units

NSAID: non-steroidal anti-inflammatory drug

$\mathrm{RCT}$ : randomised controlled trial

VAS: visual analogue scale

VPS: verbal pain scale

\section{DATA AND ANALYSES}

\section{Comparison 1. Topical NSAIDs versus Control}

\begin{tabular}{lllll}
\hline Outcome or subgroup title & No. of studies & $\begin{array}{l}\text { No. of partici- } \\
\text { pants }\end{array}$ & Statistical method & Effect size \\
\hline $\begin{array}{l}1 \text { Use of rescue oral analgesia at } 24 \\
\text { hours }\end{array}$ & 4 & 481 & $\begin{array}{l}\text { Risk Ratio (M-H, Random, } \\
95 \% \mathrm{Cl})\end{array}$ & $0.46[0.34,0.61]$ \\
\hline
\end{tabular}




\begin{tabular}{|c|c|c|c|c|}
\hline Outcome or subgroup title & No. of studies & $\begin{array}{l}\text { No. of partici- } \\
\text { pants }\end{array}$ & Statistical method & Effect size \\
\hline $\begin{array}{l}2 \text { Proportion of abrasions healed af- } \\
\text { ter } 24 \text { hours }\end{array}$ & 1 & & $\begin{array}{l}\text { Risk Ratio (M-H, Fixed, 95\% } \\
\mathrm{Cl} \text { ) }\end{array}$ & $\begin{array}{l}\text { Totals not select- } \\
\text { ed }\end{array}$ \\
\hline $\begin{array}{l}3 \text { Proportion of abrasions healed af- } \\
\text { ter } 48 \text { hours }\end{array}$ & 1 & & $\begin{array}{l}\text { Risk Ratio (M-H, Fixed, 95\% } \\
\mathrm{Cl})\end{array}$ & $\begin{array}{l}\text { Totals not select- } \\
\text { ed }\end{array}$ \\
\hline 4 Complications of corneal abrasion & 6 & 609 & $\begin{array}{l}\text { Risk Ratio (M-H, Random, } \\
95 \% \mathrm{Cl})\end{array}$ & $0.44[0.07,2.96]$ \\
\hline 5 Drug-related adverse events & 2 & 163 & $\begin{array}{l}\text { Risk Ratio (M-H, Fixed, 95\% } \\
\mathrm{Cl} \text { ) }\end{array}$ & $2.95[0.32,27.60]$ \\
\hline
\end{tabular}

Analysis 1.1. Comparison 1 Topical NSAIDs versus Control, Outcome 1 Use of rescue oral analgesia at 24 hours.

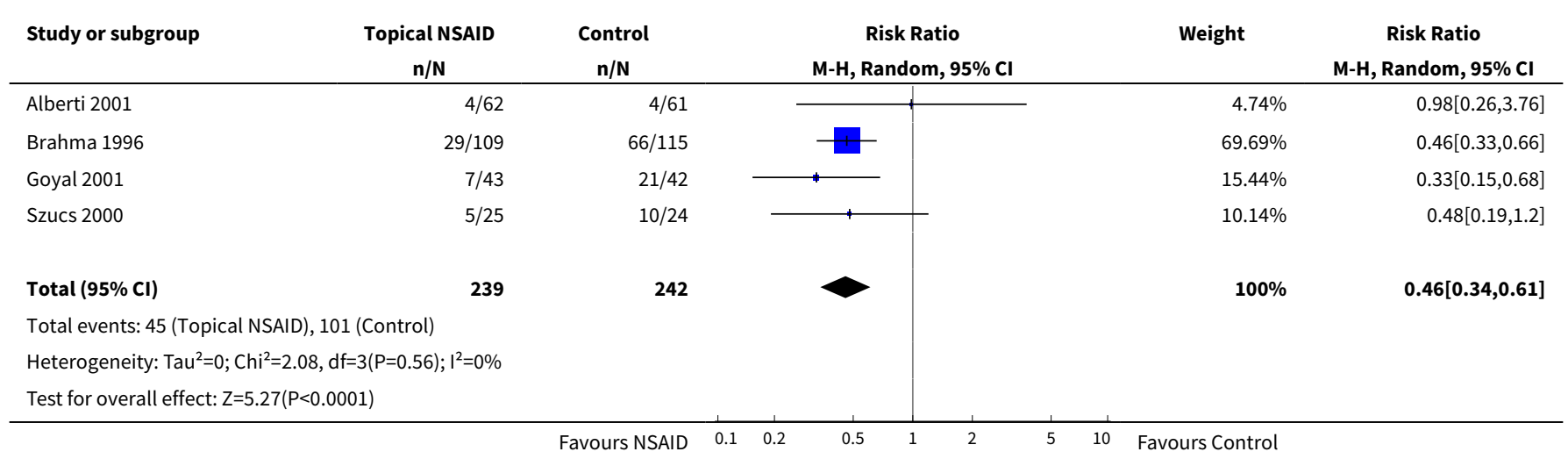

Analysis 1.2. Comparison 1 Topical NSAIDs versus Control, Outcome 2 Proportion of abrasions healed after 24 hours.

\begin{tabular}{|c|c|c|c|c|}
\hline Study or subgroup & $\begin{array}{c}\text { Favours NSAID } \\
n / N\end{array}$ & $\begin{array}{c}\text { Control } \\
n / N\end{array}$ & $\begin{array}{c}\text { Risk Ratio } \\
\text { M-H, Fixed, 95\% Cl }\end{array}$ & $\begin{array}{c}\text { Risk Ratio } \\
\text { M-H, Fixed, } 95 \% \mathrm{Cl}\end{array}$ \\
\hline Solomon 2000 & $13 / 14$ & $13 / 14$ & \begin{tabular}{l|l} 
& \\
\end{tabular} & $1[0.81,1.23]$ \\
\hline
\end{tabular}

Analysis 1.3. Comparison 1 Topical NSAIDs versus Control, Outcome 3 Proportion of abrasions healed after 48 hours.

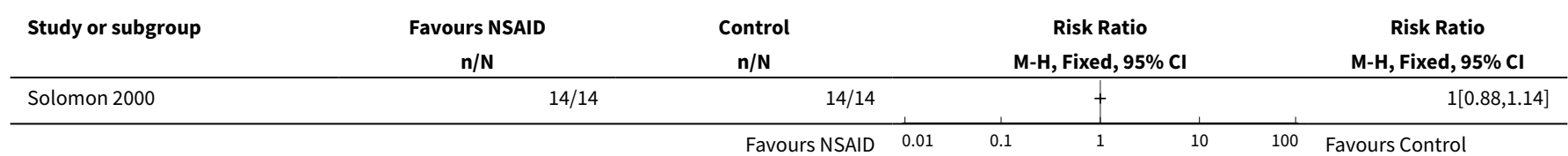


Analysis 1.4. Comparison 1 Topical NSAIDs versus Control, Outcome 4 Complications of corneal abrasion.

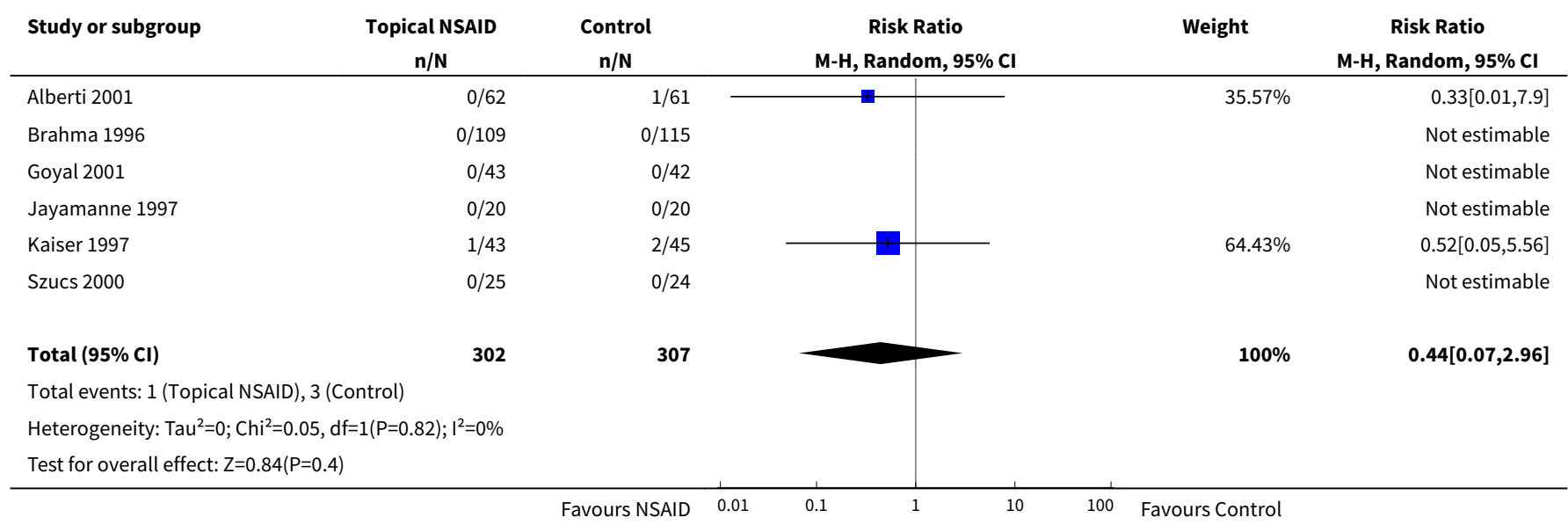

Analysis 1.5. Comparison 1 Topical NSAIDs versus Control, Outcome 5 Drug-related adverse events.

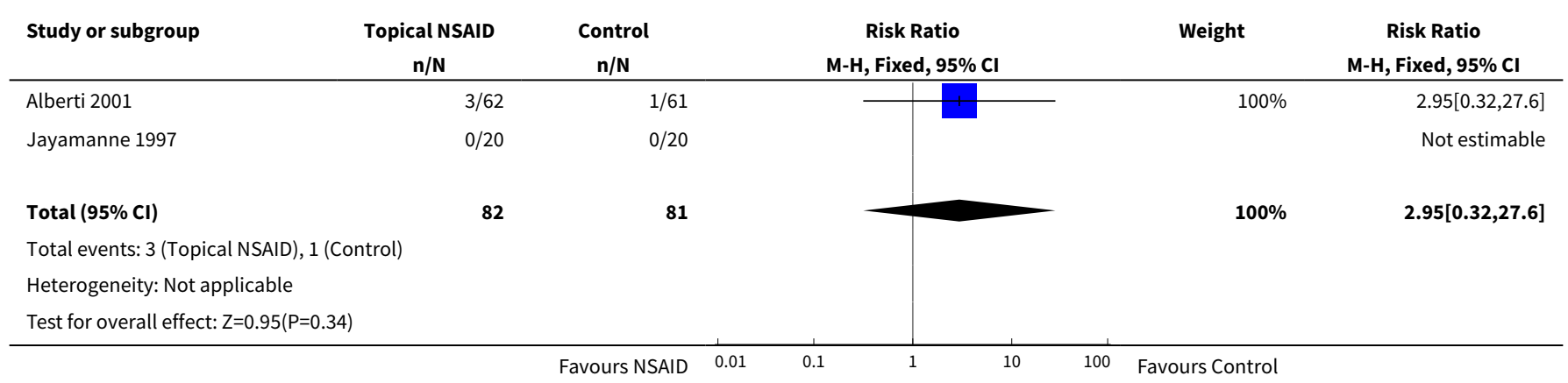

ADDITIONAL TABLES

Table 1. Comparator interventions of included studies

\begin{tabular}{|c|c|c|c|c|}
\hline Study & Intervention 1 & Intervention 2 & Comparator 1 & Comparator 2 \\
\hline Alberti 2001 & $\begin{array}{l}\text { Topical NSAID (indomethacin 0.1\%) + } \\
\text { topical antibiotic }\end{array}$ & None & Topical antibiotic & None \\
\hline Brahma 1996 & $\begin{array}{l}\text { Topical NSAID (flurbiprofen 0.03\%) + topi- } \\
\text { cal antibiotic }\end{array}$ & $\begin{array}{l}\text { Topical NSAID } \\
+ \text { cycloplegic }+ \\
\text { topical antibiotic }\end{array}$ & $\begin{array}{l}\text { Placebo + topical antibiot- } \\
\text { ic }\end{array}$ & $\begin{array}{l}\text { Cycloplegic }+ \\
\text { topical antibiotic }\end{array}$ \\
\hline $\begin{array}{l}\text { Donnenfeld } \\
1995\end{array}$ & $\begin{array}{l}\text { Topical NSAID (ketorolac } 0.5 \%)+ \\
\text { cycloplegic + topical antibiotic + bandage } \\
\text { CL }\end{array}$ & None & $\begin{array}{l}\text { Cycloplegic + topical an- } \\
\text { tibiotic + bandage CL }\end{array}$ & $\begin{array}{l}\text { Cycloplegic }+ \\
\text { topical antibiotic } \\
+ \text { pressure patch }\end{array}$ \\
\hline Goyal 2001 & $\begin{array}{l}\text { Topical NSAID (ketorolac } 0.5 \%)+ \text { cyclo- } \\
\text { plegic + topical antibiotic }\end{array}$ & None & $\begin{array}{l}\text { Placebo }+ \text { cycloplegic }+ \\
\text { topical antibiotic }\end{array}$ & None \\
\hline
\end{tabular}


Table 1. Comparator interventions of included studies (Continued)

\begin{tabular}{lllll}
$\begin{array}{l}\text { Jayamanne } \\
1997\end{array}$ & $\begin{array}{l}\text { Topical NSAID (diclofenac 0.1\%)+ topical } \\
\text { antibiotic }\end{array}$ & None & $\begin{array}{l}\text { Placebo + topical antibiot- } \\
\text { ic }\end{array}$ & None \\
\hline Kaiser 1997 & $\begin{array}{l}\text { Topical NSAID (ketorolac 0,1\%)+ cyclo- } \\
\text { plegic + topical antibiotic }\end{array}$ & None & $\begin{array}{l}\text { Placebo + cycloplegic + } \\
\text { topical antibiotic }\end{array}$ & None \\
\hline Patrone 1999 & $\begin{array}{l}\text { Topical NSAID (indomethacin 0.1\%)+ } \\
\text { topical antibiotic + bandage CL }\end{array}$ & None & $\begin{array}{l}\text { Topical antibiotic + ban- } \\
\text { dage CL }\end{array}$ & None \\
\hline Solomon 2000 & $\begin{array}{l}\text { Topical NSAID indomethacin } 1 \%)+ \text { cyclo- } \\
\text { plegic + topical antibiotic }\end{array}$ & None & $\begin{array}{l}\text { Cycloplegic + topical an- } \\
\text { tibiotic + pressure patch }\end{array}$ & None \\
\hline Szucs 2000 & Topical NSAID (diclofenac 0.1\%) + & None & $\begin{array}{l}\text { Placebo+ cycloplegic + } \\
\text { topical antibiotic }\end{array}$ & None \\
\hline
\end{tabular}

$\mathrm{CL}$ : contact lens

NSAID: non-steroidal anti-inflammatory drug

\section{APPENDICES}

\section{Appendix 1. CENTRAL search strategy}

\#1 MeSH descriptor Cornea

\#2 MeSH descriptor Corneal Diseases

\#3 MeSH descriptor Eye Injuries

\#4 (\#1 OR \#2 OR \#3)

\#5 MeSH descriptor Wounds and Injuries

\#6 injur ${ }^{\star}$ or abrasion* or erosion* or trauma* or wound ${ }^{\star}$ or foreign bod ${ }^{\star}$

\#7 (\#5 OR \#6)

$\# 8$ eye $^{\star}$ or cornea*

\#9 (\#7 AND \#8)

\#10 (\#4 OR \#9)

\#11 MeSH descriptor Anti-Inflammatory Agents, Non-Steroidal

\#12 nsaid $^{*}$

\#13 nonsteroidal anti-inflammator ${ }^{*}$

\#14 non-steroidal anti-inflammator ${ }^{\star}$

\#15 MeSH descriptor Diclofenac

$\# 16$ diclofenac*

\#17 fenoprofen*

\#18 flurbiprofen*

\#19 MeSH descriptor Indomethacin

\#20 indometacin*

\#21 MeSH descriptor Ketoprofen

\#22 ketoprofen*

\#23 ketorolac*

\#24 piroxicam*

\#25 bromfenac*

\#26 nepafenac*

\#27 oxyphenbutazone*

\#28 suprofen*

\#29 (\#11 OR \#12 OR\#13 OR \#14 OR \#15 OR \#16 OR \#17 OR \#18 OR \#19 OR \#20 OR \#21 OR \#22 OR \#23 OR \#24 OR \#25 OR \#26 OR \#27 OR \#28)

\#30 MeSH descriptor Analgesia

$\# 31$ analgesi*

\#32 MeSH descriptor Pain

\#33 pain*

\#34 (\#30 OR \#31 OR \#32 OR \#33)

Topical non-steroidal anti-inflammatory drugs for analgesia in traumatic corneal abrasions (Review) 
\#35 (\#10 AND \#29 AND \#34)

\section{Appendix 2. MEDLINE OVID search strategy}

1. randomized controlled trial.pt.

2. (randomized or randomised).ab,ti.

3. placebo.ab,ti.

4. dt.fs.

5. randomly.ab,ti.

6. trial.ab,ti.

7. groups.ab,ti.

8. or/1-7

9. exp animals/

10. exp humans/

11. 9 not (9 and 10)

12. 8 not 11

13. exp cornea/

14. exp corneal diseases/

15. exp eye injuries/

16. or/13-15

17. exp "wounds and injuries"/

18. (injur $\$$ or abrasion\$ or erosion\$ or trauma\$ or wound\$ or foreign bod\$).tw.

19. or $/ 17-18$

20. (eye\$ or cornea\$).tw.

21. 19 and 20

22. 16 or 21

23. exp anti inflammatory agents non steroidal/

24. nsaid\$.tw.

25. nonsteroidal anti-inflammator\$.tw.

26. non-steroidal anti-inflammator\$.tw.

27. exp diclofenac/

28. diclofenac\$.tw.

29. fenoprofen $\$ . t w$.

30. flurbiprofen\$.tw.

31. exp indometacin/

32. indometacin\$.tw.

33. exp ketoprofen/

34. ketoprofen\$.tw.

35. ketorolac\$.tw.

36. piroxicam\$.tw.

37. bromfenac\$.tw.

38. nepafenac\$.tw.

39. oxyphenbutazone\$.tw.

40. suprofen\$.tw.

41. or/23-40

42. exp analgesia/

43. analgesi\$.tw.

44. Pain/

45. pain\$.tw.

46. or/42-45

47. 22 and 41 and 46

48. 12 and 47

The search filter for trials at the beginning of the MEDLINE strategy is from the published paper by Glanville 2006.

\section{Appendix 3. Embase OVID search strategy}

1. exp randomized controlled trial/

2. exp randomization/

3. exp double blind procedure/

4. exp single blind procedure/

5. random\$.tw.

6. or/1-5

Topical non-steroidal anti-inflammatory drugs for analgesia in traumatic corneal abrasions (Review) 
7. (animal or animal experiment).sh.

8. human.sh.

9. 7 and 8

10.7 not 9

11.6 not 10

12. exp clinical trial/

13. (clin\$ adj3 trial\$).tw.

14. ((singl\$ or doubl\$ or trebl\$ or tripl\$) adj3 (blind\$ or mask\$)).tw.

15. exp placebo/

16. placebo\$.tw.

17. random\$.tw.

18. exp experimental design/

19. exp crossover procedure/

20. exp control group/

21. exp latin square design/

22. or/12-21

23. 22 not 10

24. 23 not 11

25. exp comparative study/

26. exp evaluation/

27. exp prospective study/

28. (control\$ or prospectiv\$ or volunteer\$).tw.

29. or $/ 25-28$

30.29 not 10

31.30 not $(11$ or 23$)$

32. 11 or 24 or 31

33. exp cornea/

34. exp cornea disease/

35. exp cornea epithelium/

36. exp eye injury/

37. or/33-36

38. exp injury/

39. (injur\$ or abrasion\$ or erosion\$ or trauma\$ or wound\$ or foreign bod\$).tw.

40. or/38-39

41. (eye\$ or cornea\$).tw.

42.40 and 41

43. 37 or 42

44. exp nonsteroidal antiinflammatory agent/

45. nsaid\$.tw.

46. nonsteroidal anti-inflammator\$.tw.

47. non-steroidal anti-inflammator\$.tw.

48. exp diclofenac/

49. diclofenac\$.tw.

50. fenoprofen\$.tw.

51. flurbiprofen $\$$.tw.

52. exp indometacin/

53. indometacin\$.tw.

54. exp ketoprofen/

55. ketoprofen\$.tw.

56. ketorolac\$.tw.

57. exp piroxicam/

58. piroxicam\$.tw.

59. bromfenac\$.tw.

60. nepafenac\$.tw.

61. oxyphenbutazone\$.tw.

62. suprofen\$.tw.

63. or/44-62

64. exp analgesia/

65. analgesi\$.tw.

66. eye pain/

67. pain\$.tw.

68. or/64-67

Topical non-steroidal anti-inflammatory drugs for analgesia in traumatic corneal abrasions (Review) 
69. 43 and 63 and 68

70. 32 and 69

\section{Appendix 4. LILACS search strategy}

injur\$ or abrasion or erosion or trauma or foreign bod\$ and eye\$ or cornea\$ and nonsteroidal antiinflammator\$ or nonsteroidal anti inflammator\$ or non steroidal anti inflammator\$ or NSAID\$ or diclofenac or fenoprofen or flurbiprofen or indometacin or ketoprofen or ketorolac or piroxicam or bromfenac or nepafenac or oxyphenbutazone or suprofen and analgesi\$ or pain\$

\section{Appendix 5. OpenGrey search strategy}

corneal abrasion and pain

\section{Appendix 6. Zetoc search strategy}

corneal abrasion and pain

\section{Appendix 7. ISRCTN search strategy}

corneal abrasion and pain

\section{Appendix 8. ClinicalTrials.gov search strategy}

Corneal Abrasion AND Pain

\section{Appendix 9. WHO ICTRP search strategy}

Corneal Abrasion AND Pain

Appendix 10. Risk of bias assessment

\begin{tabular}{|c|c|c|}
\hline \multicolumn{3}{|l|}{ Risk of bias assessment (RoB assessment) } \\
\hline Entry & Judgement & $\begin{array}{l}\text { Support for judge- } \\
\text { ment }\end{array}$ \\
\hline 1. Random sequence generation (selection bias) & Low risk/High risk/Unclear risk & Quote: \\
\hline 2. Allocation concealment (selection bias) & Low risk/High risk/Unclear risk & Quote: \\
\hline $\begin{array}{l}\text { 3. Masking of participants and personnel (performance } \\
\text { bias) }\end{array}$ & Low risk/High risk/Unclear risk & Quote: \\
\hline 4. Masking of outcome assessment (detection bias) & Low risk/High risk/Unclear risk & Quote: \\
\hline 5. Incomplete outcome data & Low risk/High risk/Unclear risk & Quote: \\
\hline Date:_/_/_ & Reviewer's signature: & \\
\hline
\end{tabular}

\section{CONTRIBUTIONS OF AUTHORS}

Abel Wakai (AW) wrote the drafts for the protocol/review and performed the GRADE assessment.

John Lawrenson (JL), Annali Lawrenson (AL), Ahmed Amayem (AA), Eddy Lang (EL) and Cathal Walsh (CW) reviewed and commented on the drafts.

Ryan McCormick (RM) and Omar Ghandour (OG) independently assessed the titles and abstracts of studies identified for relevance and design.

Michael Brown (MB) and Michael Quirke (MQ) independently abstracted data from the included studies and independently assessed and rated the methodological quality of each included study using the Cochrane tool for assessing risk of bias.

Yongjun Wang (YW) performed the GRADE assessment.

AW and JL responded to peer review comments. 


\section{DECLARATIONS OF INTEREST}

Abel Wakai: none known John Lawrenson: none known Annali Lawrenson: none known Yongjun Wang: none known Michael Brown: none known Michael Quirke: none known Omar Ghandour: none known Ryan McCormick: none known Cathal Walsh: none known Ahmed Amayem: none known Eddy Lang: none known Nick Harrison: none known

\section{SOURCES OF SUPPORT}

\section{Internal sources}

- No sources of support supplied

\section{External sources}

- National Institute for Health Research (NIHR), UK.

- Richard Wormald, Co-ordinating Editor for Cochrane Eyes and Vision (CEV) acknowledges financial support for his CEV research sessions from the Department of Health through the award made by the NIHR to Moorfields Eye Hospital NHS Foundation Trust and UCL Institute of Ophthalmology for a Specialist Biomedical Research Centre for Ophthalmology.

- This review was supported by the NIHR, via Cochrane Infrastructure funding to the CEV UK editorial base.

The views and opinions expressed therein are those of the authors and do not necessarily reflect those of the Systematic Reviews Programme, NIHR, NHS or the Department of Health.

\section{DIFFERENCES BETWEEN PROTOCOL AND REVIEW}

In the protocol we stated that we would make additional efforts to identify potential RCTs relevant to the topic from the following data sources: references (and references of references) cited in primary sources; other unpublished sources known to experts in the specialty, raw data from published trials; contacting pharmaceutical companies. In this review, due to the comprehensive nature of our electronic searches, we did not seek information regarding potential RCTs relevant to the topic from known experts in the specialty or from pharmaceutical companies, and we did not seek raw data from the published trials.

We stated in the protocol that dichotomous outcomes would be described using relative (risk ratio) and absolute (risk difference) measures. In this review we only calculated risk ratios. Measures of absolute risk are included in the summary of findings table.

\section{N DEX TERMS}

\section{Medical Subject Headings (MeSH)}

Administration, Topical; Anti-Inflammatory Agents, Non-Steroidal [ ${ }^{*}$ administration \& dosage] [adverse effects]; Corneal Injuries [complications] [ ${ }^{*}$ drug therapy]; Diclofenac [administration \& dosage]; Flurbiprofen [administration \& dosage]; Indomethacin [administration \& dosage]; Ketorolac [administration \& dosage]; Pain Measurement; Randomized Controlled Trials as Topic; Wound Healing

\section{MeSH check words}

Humans 